Produto \& Produção, vol. 11, n. 2, p. 26 - 54, jun. 2010

\title{
Simulação de Monte Carlo Aplicada à Decisão de Mix de Produtos
}

\author{
Abraão Freires Saraiva Júnior \\ Engenheiro, Mestre e Doutorando em Engenharia de Produção \\ Escola Politécnica da Universidade de São Paulo \\ abraaofsji@gmail.com \\ Maxweel Veras Rodrigues \\ Doutor e Professor do Departamento de Engenharia de Produção \\ Centro de Tecnologia da Universidade Federal do Ceará \\ maxweelveras@gmail.com \\ Reinaldo Pacheco da Costa \\ Doutor e Professor do Departamento de Engenharia de Produção \\ Escola Politécnica da Universidade de São Paulo \\ rpcosta@usp.br
}

\begin{abstract}
RESUMO
Este artigo objetiva apresentar a utilização da simulação de Monte Carlo no processo de definição de métricas para fundamentar a decisão de mix de produtos em uma empresa cujos produtos possuem grande variabilidade de custos unitários. Para cumprir este objetivo, é proposto um método de sete etapas que é construído a partir da integração da simulação de Monte Carlo com o conceito de Margem de Contribuição, provindo da Contabilidade Gerencial. O método é aplicado a partir de um exemplo didático que utiliza dados reais obtidos através de uma pesquisa de campo realizada em uma indústria de produtos plásticos brasileira que utiliza material reciclado. Por fim, conclui-se que a simulação de Monte Carlo é útil no tratamento da variabilidade de custos unitários e que o método de suporte à tomada de decisão de mix de produtos proposto é válido.
\end{abstract}

Palavras-chave: Decisão de mix de produtos, simulação de Monte Carlo, variabilidade de custos unitários. 


\section{INTRODUÇÃO}

Quando uma empresa se depara com a situação em que a demanda por seus produtos cresce ao ponto de ser maior que a capacidade de fornecimento, e que não há disponibilidade de capital para expansão desta, algum critério ou métrica deve ser estabelecido para alicerçar a priorização de produção e venda dos produtos, ou seja, a decisão de mix de produtos da empresa. A definição desse critério ou métrica, geralmente, passa por discutir formas de melhoria do resultado econômico da empresa (FREDENDALL; LEA, 1997). Para tal, é importante que se faça um levantamento e uma análise de informações referentes à estrutura e ao comportamento dos custos e dos preços de venda praticados pela empresa (LEONE, 2000). Uma das métricas de suporte à decisão existente é a Margem de Contribuição que possui mensuração econômica. Pode-se também considerar outros critérios como qualidade, concorrência, participação no mercado, entre outros. Porém, estes podem fazer com que a decisão não se paute exclusivamente pelo resultado econômico da empresa (PADOVEZE, 2006).

Em alguns processos de produção, o levantamento e análise de custos são dificultados devido à existência de produtos que possuem elevada variabilidade de utilização de recursos e que geram incertezas aos tomadores de decisão. Tem-se, como exemplo, a indústria de fabricação de produtos plásticos a partir de materiais reciclados em que se observa uma considerável variabilidade dos custos unitários, variabilidade esta ocasionada pela alternância da quantidade de material e do tempo de processamento demandados por cada unidade produzida. Dentro desse contexto, levanta-se o seguinte questionamento que baliza o estudo: como estabelecer um critério que alicerce a decisão de mix de produtos de uma empresa cujos produtos apresentam grande variabilidade de custos unitários? Para responder a esse questionamento, o presente estudo faz o uso de conceitos e técnicas provindos da Contabilidade Gerencial e da Pesquisa Operacional.

Após esta introdução, o artigo é estruturado a partir de uma seção de metodologia seguida de uma seção de fundamentação teórica em que se discute o conceito de Margem de Contribuição e sua utilização na decisão de mix de produtos, além de aspectos inerentes à simulação, com destaque ao método de Monte Carlo. $\mathrm{Na}$ quarta seção, é proposto um método para alicerçar a decisão de mix de produtos em um cenário de variabilidade de custos unitários. A seção cinco expõe uma aplicação do método proposto a partir de dados e informações coletados em uma indústria de artefatos plásticos brasileira, bem como os resultados obtidos. Na última seção, são expostas as considerações finais dos autores.

\section{METODOLOGIA}

Para responder à pergunta de pesquisa, na seção de Introdução posta como "questionamento", este estudo foi desenvolvido em três momentos. Com o intuito de encontrar conceitos, teorias e técnicas que fundamentassem a construção de uma resposta para a pergunta de pesquisa, foi realizada uma (i) pesquisa bibliográfica que, de acordo com Gil (2002, p.44), "é desenvolvida com base em material já elaborado, constituído principalmente de livros e artigos". Primeiramente, a pesquisa 
bibliográfica envolveu a busca de publicações, no campo da Contabilidade Gerencial, que compreendessem alguma métrica econômico-financeira envolvendo a tomada de decisão de mix de produtos. Em seguida, foram buscadas, no campo da Pesquisa Operacional, publicações que versassem sobre técnicas quantitativas que compreendessem $o$ tratamento de variabilidade e que pudessem ser trabalhadas de forma integrada com a métrica prospectada inicialmente na pesquisa bibliográfica.

De posse do arcabouço teórico prospectado, realizou-se a (ii) proposição de um método para auxiliar a tomada de decisão de mix de produtos. O método constitui-se de sete etapas organizadas de forma seqüencial e abordadas, principalmente, a partir de expressões matemáticas e de simulação. Em seguida, o método proposto foi aplicado em um processo produtivo a partir de um exemplo didático que foi respaldado por uma (iii) pesquisa de campo realizada em uma indústria brasileira de artefatos plásticos que manufatura produtos a partir de material plástico reciclado. Conforme Marconi e Lakatos (2008, p.188), uma pesquisa de campo "consiste na observação de fatos e fenômenos tal como ocorrem espontaneamente, na coleta de dados a eles referentes e no registro de variáveis que se presumem relevantes, para analisá-los". Desta forma, foram realizadas entrevistas com pessoas-chave e coletados dados e informações in loco na empresa para se levantar elementos reais relativos ao processo produtivo, à estrutura de produto, aos gastos (soma dos custos e despesas) e aos preços de venda praticados. As principais fontes de evidência coletadas na pesquisa de campo (adaptando os termos de Yin (2005) voltados para o planejamento de estudos de caso) são apresentadas no quadro 1:

\begin{tabular}{|l|l|}
\hline \multicolumn{1}{|c|}{ Fonte de Evidências } & \multicolumn{1}{c|}{ Principais Elementos Trabalhados e Materiais Coletados } \\
\hline Documentação & $\begin{array}{l}\text { - Memorial descritivo do processo produtivos da empresa } \\
\text { - Mapa de localização de custos } \\
\text { - Especificações técnicas de produtos e de equipamentos }\end{array}$ \\
\hline Registros em arquivos & $\begin{array}{l}\text { - Relatórios contábeis mensais } \\
\text { - Planilhas de centros de custos } \\
\text { - Contas de energia }\end{array}$ \\
\hline $\begin{array}{l}\text { Entrevistas } \\
\text { (semi-estruturadas) }\end{array}$ & $\begin{array}{l}\text { - Diretor Industrial } \\
\text { - Diretor Financeiro } \\
\text { - 2 supervisores de produção } \\
\text { - Responsável pela controladoria da empresa }\end{array}$ \\
\hline Observações diretas & $\begin{array}{l}\text { - Observação de uma reunião de discussão do setor de supervisão de } \\
\text { produção }\end{array}$ \\
\hline Observação participante & - Participação em 3 reuniões com os diretores da empresa \\
\hline Artefatos físicos & - Quadro com índices de refugo mensais \\
\hline
\end{tabular}

Quadro 1 - Fontes de evidências coletadas na pesquisa de campo

Fonte: autores

Na empresa estudada, dada a existência de uma variabilidade acentuada na qualidade da matéria-prima (plástico reciclado), foram identificadas quatro variáveis com comportamento aleatório que são fontes de incertezas e que impactam o custo unitário, quais sejam: quantidade de matéria-prima, tempo de processamento dos produtos, mão-de-obra e energia. Além disso, informações sobre preço de venda e despesas com comissões sobre vendas foram trabalhadas probabilisticamente. Para completar o exemplo didático e inseri-lo no contexto da pergunta de pesquisa, estabeleceu-se um cenário hipotético com a assunção de algumas suposições sobre as condições envolvidas com a decisão de mix de produto a ser tomada. Em 
seguida, dentro do cenário construído, os dados e as informações coletadas foram trabalhados e apresentados em planilhas eletrônicas para facilitar aplicação do método proposto e a visualização dos resultados alcançados.

\section{FUNDAMENTAÇÃO TEÓRICA}

\subsection{Margem de contribuição}

Para que se compreenda o conceito da Margem de Contribuição, provindo do campo de conhecimento da Contabilidade Gerencial, é preciso, primeiramente, que se entenda a abordagem do Método de Custeio Variável (MCV). Martins (2006, p. 198) argumenta que "no MCV, somente os custos variáveis são alocados aos produtos, ficando os fixos separados e considerados como despesas do período, indo diretamente para o resultado". Também chamado por alguns autores de custeio direto (ex: FOSTER; BAXENDALE, 2008), o MCV, ao identificar os custos de comportamento variável, permite uma análise gerencial em função do grau de participação de cada componente de custo no valor global do objeto de custo (produtos, pedidos, clientes, segmentos da empresa, entre outros) trazendo conclusões objetivas do ponto de vista gerencial (GARRISON et al., 2006). Embora seja utilizado para fins de tomada de decisões gerenciais, o MCV não é adequado em relação à legislação e às normas contábeis e fiscais brasileiras (BRUNI, 2006).

Derivada do custeamento variável, a Margem de Contribuição (MC) é caracterizada pela diferença entre a receita e a soma de custos e despesas variáveis, fazendo com que seja evidenciado o valor que cada unidade produzida, linha de produto, pedido ou cliente proporciona à empresa de sobra entre a sua receita e o custo que de fato tenha provocado (MARTINS, 2006). Os custos fixos são subtraídos desta margem de contribuição para se obter o lucro operacional líquido. A MC propicia informações ao gerente para decidir se é coerente diminuir ou expandir uma linha de produção, para avaliar as alternativas provenientes do mix de produtos, para verificar se é economicamente interessante aceitar um pedido ou não, além de verificar quais produtos, pedidos e clientes são mais lucrativos para a empresa (ASSEF, 2005). Quando a unidade de mensuração é uma unidade de produto, tem-se a Margem de Contribuição Unitária (MCU). Na situação em que a MCU é utilizada isoladamente como critério econômico para alicerçar a priorização da produção e venda de produtos, Linhares (2009) denomina a lógica de decisão de mix de produtos de "heurística da margem" (margin heuristic).

Por sua vez, a lógica de decisão de mix de produtos que considera, além da MCU, o consumo que cada tipo de produto (por unidade produzida) realiza do recurso cuja capacidade de produção é menor ou igual à demanda por seus serviços - também chamado de recurso com restrição de capacidade (RRC) ou restrição do sistema (CORBETT NETO, 1997; COX III; SPENCER, 1998) -, é denominada por Linhares (2009) como "heurística derivada da Teoria das Restrições - TOC" (TOCderived heuristic). Convém ressaltar que a heurística derivada da TOC aplica-se em situações em que se prevê que a capacidade de fornecimento da empresa será sobrepujada pela demanda, ou seja, que haverá algum recurso gargalo interno ao processo produtivo (SINGH et al., 2006). Em sua concepção restrita, a heurística derivada da TOC considera apenas o custo de matérias-primas como custo a ser 
considerado no critério de decisão de mix de produtos. No entanto, tal como argumentam Demmy e Talbott (1998) e Cogan (2007), a suposição de que matériasprimas são os únicos custos variáveis é simplesmente não verdadeira para muitas companhias e processos produtivos. Desta forma, outros custos e despesas também podem ter comportamento variável e serem atribuídos diretamente aos produtos (ex: mão-de-obra, utilidades e comissões sobre vendas) para comporem o critério de decisão de mix de produtos, ou seja, a MCU que é dividida pelo consumo unitário de RRC.

Ressalta-se que, em alguns processos, o cálculo da MCU pode ser impactado por incertezas contábeis decorrentes da variabilidade dos itens que compõem a MCU, tais como: custos variáveis unitários de material direto, de mão-de-obra direta e de utilidades (ex: energia, água, ar-comprimido); despesas variáveis unitárias (ex: comissões de venda e frete de entrega); e preços de venda (PADOVEZE; 2006). Fazer estimativas ou projeções dos itens que compõem a MCU demanda um conhecimento de dados históricos e das condições mercadológicas envolvidas com o negócio. Para tal, podem ser aplicadas estatísticas descritivas nesses dados para projetar os gastos e preços de venda do período seguinte. Essa projeção torna-se dificultada quando, na empresa, há uma grande variabilidade de gastos e receitas por produto. Essa variabilidade pode ser trabalhada através de técnicas de simulação.

\subsection{Simulação}

Inserida no campo de conhecimento da Pesquisa Operacional, a simulação é uma representação da operação de um processo ou sistema real, num dado período de tempo, que envolve a geração de uma história artificial desse sistema e a observação desta para fazer inferências relativas às características do processo real (BANKS et al., 1996). Hillier e Liberman (1995) indicam que a realização de uma simulação inicia-se com o desenvolvimento de um modelo que represente o sistema a ser investigado, modelo este que, no entendimento de Pidd (1996), consiste em uma representação explícita e externa de um extrato parcial da realidade vista pela pessoa que deseja usar um modelo para entender, mudar, gerenciar, indicar políticas e controlar parte daquela realidade. A simulação tem sido utilizada na engenharia para tratar situações em que se tenta compreender características de um sistema pelo conhecimento de outro que lhe é similar (PRADO, 2004), sendo especialmente útil em situações que envolvem análise de riscos (LUSTOSA et al., 2004). Buffa (1973) e Winston (1994) sugerem que uma forma de simular um sistema, considerando o comportamento do tipo de variáveis que se pretende analisar, é através do desenvolvimento de um modelo de simulação utilizando distribuições de freqüência de eventos discretos conhecido como método simulação de Monte Carlo, versado a seguir.

\subsubsection{Método de simulação de Monte Carlo}

A simulação de Monte Carlo (SMC) envolve o uso de números aleatórios e probabilidades para analisar e resolver problemas. A SMC surgiu no Projeto 
Manhattan do laboratório de armas nucleares Los Alamos, Estados Unidos, durante a Segunda Guerra Mundial, sendo desenvolvido pelos cientistas John Von Neumann e Stanislaw Ulam. A denominação "Monte Carlo" foi cunhada em referência aos jogos de azar que fazem uso constante de sorteios e de dados, uma atração popular na cidade de Monte Carlo, Mônaco (METROPOLIS; ULAM, 1949, METROPOLIS, 1987).

No entendimento de Lustosa et al. (2004, p.251), a simulação de Monte Carlo consiste em um método que "utiliza a geração de números aleatórios para atribuir valores às variáveis do sistema que se deseja investigar". Os números são obtidos através de artifícios aleatórios (ex: tabelas, roletas, sorteios) ou diretamente de softwares, através de funções específicas (para obter mais detalhes sobre métodos de obtenção de números aleatórios, consultar Gentle (2003)). A cada iteração, o resultado é armazenado e, ao final de todas as iterações, a seqüência de resultados gerados é transformada em uma distribuição de freqüência que possibilita calcular estatísticas descritivas, como média (valor esperado), valor mínimo, valor máximo e desvio-padrão, cabendo ainda ao executor das simulações a prerrogativa de projetar cenários futuros de operação do sistema em análise. A SMC possui aplicações em problemas de tomada de decisão que envolve risco e incerteza, ou seja, situações nas quais o comportamento das variáveis envolvidas com o problema não é de natureza determinística (MOORE; WEATHERFORD, 2001; LUSTOSA et al., 2004). Para operacionalizar a SMC, alguns passos básicos devem ser seguidos, como mostra a figura 1:

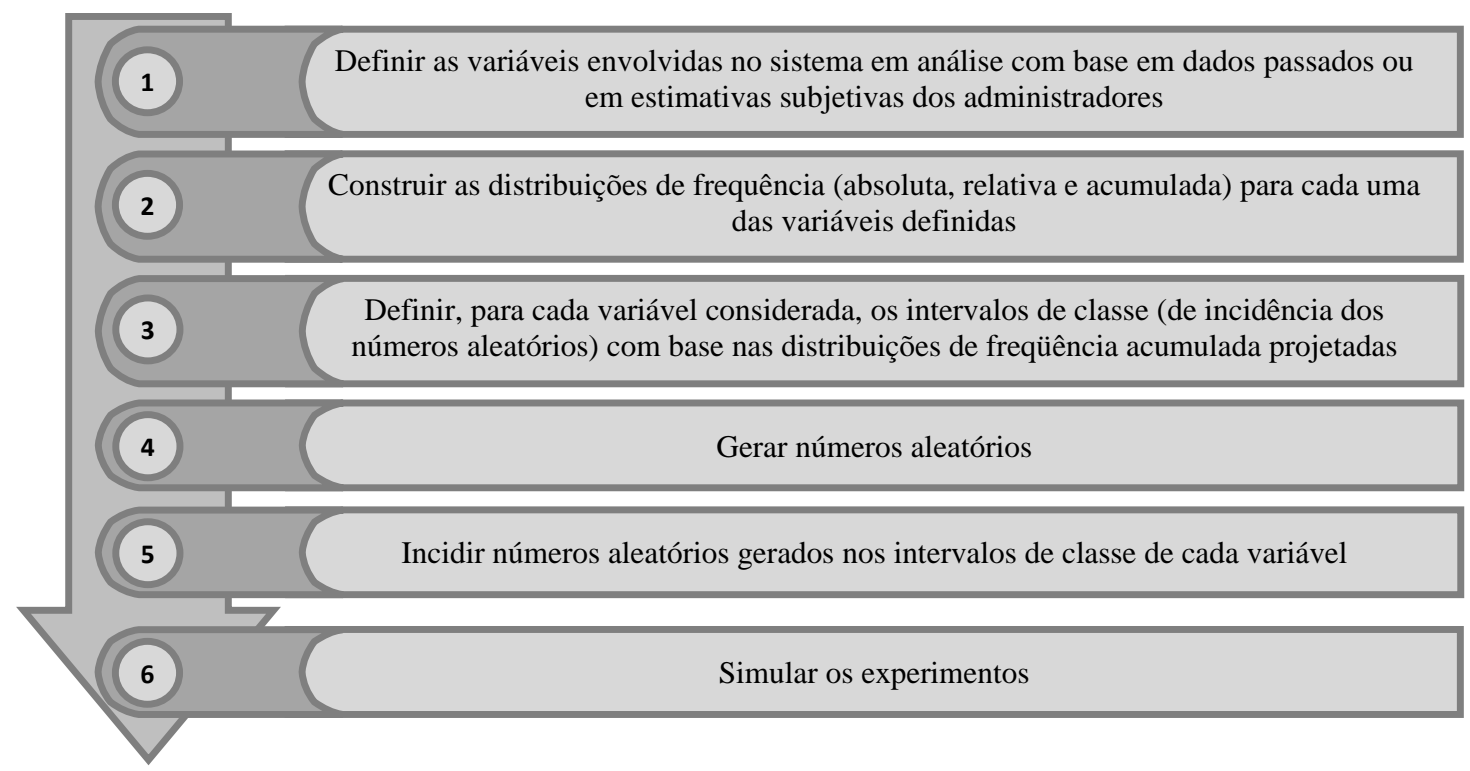

Figura 1 - Passos para operacionalização do método de simulação de Monte Carlo Fonte: Adaptado de Shamblin e Stevens (1974)

Para uma correta operacionalização da SMC, Lustosa et al. (2004) indicam que a simulação deve ser replicada mais de cem vezes para que se obtenha uma amostra representativa. No entanto, não há recomendação quanto ao número máximo de simulações a serem realizadas. Como instrução básica, deve-se aplicar o maior número de simulações possíveis levando em consideração o poder de processamento do equipamento a ser utilizado, pois o equilíbrio entre precisão e 
tempo de computação é uma característica importante das simulações baseadas na SMC (ESCUDERO, 1973).

\section{MÉTODO PROPOSTO}

Aqui é exposta a estrutura do método proposto para determinar o mix de produtos na situação em que uma indústria, que possui grande variabilidade de custos unitários, passa a ter uma capacidade de fornecimento menor do que a demanda por seus produtos. Esse método utiliza, principalmente, a Margem de Contribuição, a Simulação de Monte Carlo e o conceito de consumo unitário de RRC, buscando aproveitar o melhor que cada um pode oferecer tendo em vista a maximização do resultado econômico da empresa. O método é dividido em sete etapas com vistas a um melhor controle dos dados a analisados e dos resultados a serem apresentados.

A primeira etapa consiste na análise e projeção dos gastos unitários, ou seja, dos custos e das despesas que incidem em cada produto da empresa, devendo ser minucioso e possuir uma base de dados confiável, pois tem influência direta na decisão de mix de produtos a ser tomada numa perspectiva econômica. A segunda etapa corresponde à análise dos dados relativos aos preços de venda praticados pela empresa. A terceira etapa é a determinação da Margem de Contribuição Unitária Esperada (MCUE) dos produtos para o período em análise, etapa esta que pressupõe a posse das informações extraídas das duas etapas anteriores. A quarta etapa consiste na análise da demanda, tanto a definida na forma de pedidos em carteira, como também a demanda aleatória. A partir dessa análise, realiza-se uma projeção da demanda e da necessidade de produção para o período a ser apreciado. Na quinta etapa, é realizada uma análise de disponibilidade dos recursos produtivos da empresa. Em outras palavras, é diagnosticada a capacidade de produção das máquinas, pessoas e insumos necessários para fabricação dos produtos para verificação da existência de um Recurso com Restrição de Capacidade no processo fabril. A sexta etapa consiste na determinação, para cada produto, da métrica econômica: MCUE sobre Consumo Esperado de RRC (RRCE). Ressalta-se que, para a definição desta métrica, faz-se o uso dos resultados obtidos nas etapas três e cinco. Na etapa sete, é definido um mix de produtos com base métrica econômica definida na etapa anterior. A figura 2 mostra, esquematicamente, a estrutura do método proposto: 
Figura 2 - Estrutura do método proposto para determinação de mix de produtos Fonte: Elaborado pelos autores

Ressalta-se que as setas indicam as relações de dependências entre as etapas, ou seja, quais informações são necessárias para a realização de cada uma das etapas. As etapas são detalhadas a seguir.

\subsection{Etapa 1 - analisar e projetar gastos unitários}

Para que esta etapa seja concluída com êxito, a estrutura da empresa deve ser conhecida, incluindo o seu funcionamento, mão-de-obra utilizada, produtos fabricados, impostos incidentes, entre outros. Além disso, os objetivos estratégicos da empresa devem ser notados, pois, a partir desse conhecimento, uma visão global do negócio é obtida. Esta primeira etapa consiste no levantamento e análise de todos os custos e despesas que incidem em cada unidade fabricada e vendida de cada tipo de produto. Para tal, faz-se o uso de dados históricos de um horizonte temporal aceitável. Um estudo por um período maior que seis meses pode proporcionar uma base de dados representativa. Em seguida, é realizada uma avaliação da freqüência de incidência desses gastos a fim de projetá-los para o período de análise. Esta projeção é feita através da construção de histogramas de freqüência de utilização, por produto, de cada recurso produtivo. Vale ressaltar que, para efeito do corrente estudo, são trabalhados apenas os gastos unitários variáveis e diretos da empresa, pois os gastos indiretos e fixos são de difícil atribuição (quer não seja através de critérios arbitrários de rateio) aos produtos, tendo pouca ou nenhuma influência direta na determinação do mix de produtos no curto prazo. Essas distribuições geradas constituem a base para aplicação de simulação a ser utilizada na determinação da MCU de cada produto.

Para a execução desta etapa, primeiramente, os gastos (custos e despesas) que variam diretamente com o volume de produção e de venda devem ser 
identificados. A seguir, são apresentados os principais gastos (com acentuada variabilidade) que podem ser atribuídos unitariamente aos produtos junto ao modo que estes devem ser analisados e projetados, conforme o método proposto:

- Material Direto (MD): na situação em que o produto é feito a partir de uma mistura de matérias-prima (MP), deve-se levantar, em peso e em valor monetário, cada quantidade/tipo de MP utilizada. O levantamento do quantitativo de material consumido pode ser realizado a partir de pesagens de cada lote produzido. Davis et al. (1999) indicam que o tamanho da amostra a ser testada pode ser de cinco unidades, já que para aplicações industriais do controle de processo é preferível fazer o uso de amostras de tamanho pequeno. De posse dessas informações, calcula-se o custo da matéria-prima para cada produto, para cada lote em análise. Esses valores são projetados a partir de histogramas de freqüência e utilizados na determinação da margem de contribuição unitária do produto. Vale ressaltar que, no caso de um processo de industrialização, impostos recuperáveis como ICMS, IPI, entre outros, não valoram os custos, pois são repassados ao consumidor final.

- Mão-de-Obra Direta (MOD): consiste nos salários nominais mais os encargos sociais e benefícios dos funcionários diretamente relacionados com a fabricação dos produtos. A projeção desse tipo de custo também pressupõe uma base histórica de dados (tempo dedicado à produção de uma unidade de cada tipo de produto) e pode ser feita através de distribuição de freqüência. Como esse custo tem relação unívoca com o tempo de processamento destinado pelo operário para cada produto, pode-se fazer o uso histogramas de freqüência para projetar esses custos unitários para períodos seguintes. Os custos inerentes ao pessoal de apoio à produção, como os supervisores, gerentes, mecânicos, inspetores, faxineiros, entre outros, não compõem a base de cálculo desse gasto, pois são classificados como Custos Indiretos de Fabricação (CIF) e, normalmente, são considerados como custos fixos que não são atribuídos unitariamente aos produtos.

- Utilidades: nos casos em que a consecução de produtos pressupõe a utilização de maquinário e este é operacionalizado através de energia elétrica, determina-se quanto cada produto custa em relação ao consumo energético. Ressalta-se que esse custo está diretamente ligado ao tempo utilizado da máquina para a fabricação de cada produto, neste estudo denominado de Tempo de Ciclo (TC). Existem máquinas que medem, automaticamente, o TC para cada unidade produzida, além de oferecer um histórico das medições. Por motivos diversos, como a má qualidade da matéria-prima, por exemplo, verifica-se que esses tempos de processamento podem variar aleatoriamente. De forma similar aos itens anteriores, analisa-se o histórico de utilização das máquinas para cada produto. Em seguida, esses dados são representados através de histogramas e projetados na forma de distribuição de freqüência. Vale ressaltar que outros itens consumidos pelo maquinário podem ser tratados de forma similar à energia, tais como: água, ar comprimido, gás natural, entre outros. Para tal, basta que estes tenham a utilização mensurada e os custos calculados.

- Despesas Variáveis (DV): mesmo não relacionado diretamente com o processo produtivo em si, este tipo de gasto varia com o volume de produtos vendidos e têm influência direta na determinação da MCU quando pode ser atribuído de forma direta e unitária aos produtos. Bernardi (2004) destaca como despesas variáveis, os gastos relacionados com comissões sobre vendas e com a distribuição de produtos. 
Em suma, o output esperado desta etapa é a projeção das distribuições de freqüência de utilização de cada recurso em cada produto, junto aos valores monetários correlacionados. Para a determinação da MCU são necessárias, ainda, informações referentes às receitas unitárias. Estas são tratadas a seguir.

\subsection{Etapa 2 - analisar e projetar receitas unitárias}

Nesta etapa são analisadas e projetadas as receitas unitárias dos produtos. Como as receitas unitárias referem-se aos preços de venda praticados, esta etapa delineia-se apenas na análise de dados históricos relativos ao valor venal de cada tipo de produto. Vale ressaltar que, em muitas empresas, os preços são tabelados levando em consideração tanto fatores mercadológicos, como as práticas da concorrência, como também fatores econômicos, como a ocorrência de inflação e o aumento da tributação. Convém lembrar que, no âmbito deste estudo para fins gerenciais, o preço unitário de venda refere-se ao preço à vista e não considera o Imposto sobre Produtos Industrializados (IPI), Imposto sobre Circulação de Mercadorias e Serviços (ICMS - abreviado) ou qualquer outro imposto ou taxa que incide sobre a venda. De posse dessas informações, são construídos histogramas e realizam-se projeções na forma de distribuições de freqüência. Estas projeções são aproveitadas, através de simulação, na determinação da MCU de cada produto que a empresa fornece.

\subsection{Etapa 3 - aplicar simulação e determinar a margem de contribuição unitária esperada de cada produto}

Esta etapa consiste na determinação da MCU esperada, de cada produto, para um determinado período. A MCU compõe a métrica que serve como base para a decisão do mix de produtos da empresa. Para calcular a MCU esperada, determina-se a MCU para cada simulação e é aplicada estatística descritiva. Para tal, pode-se fazer o uso de números aleatórios gerados por algum software específico que, incidindo sobre as distribuições de freqüência extraídas das etapas anteriores, resulta em uma determinada quantidade consumida de recurso (material direto, mão-de-obra direta e utilidades) e uma correspondente receita unitária de cada produto (que pode impactar na despesa variável unitária).

Vale ressaltar que os resultados obtidos seguem a freqüência de ocorrência determinada pelas distribuições de freqüência auferidas e que, para cada simulação, um número aleatório gerado incide tanto nos recursos produtivos, quanto nas receitas unitárias. Multiplicando essas quantidades consumidas, geradas em cada simulação, pelo valor monetário de uma unidade de consumo, consegue-se determinar os gastos unitários para cada produto. Divide-se a soma desses gastos gerados por um Índice de Rendimento, cujo cálculo é exposto na equação 2. Este índice tem relação com os custos gerados pela fabricação de produtos nãoconformes com a qualidade requerida pelos clientes. A mesma sistemática aplica-se às receitas de vendas desconsiderando os produtos refugados, já que estes não são vendidos. 
Em cada sorteio ou geração de número aleatório, a probabilidade de um determinado consumo de um recurso ser obtido é igual à probabilidade ou freqüência relativa que este recurso tem em relação às demais possibilidades. Destaca-se que cada número aleatório, sendo este não-nulo, valora-se entre 0 e 1. Para o cálculo da MCU de cada produto, em cada simulação, faz-se o uso da fórmula apresentada a seguir:



Onde: $\mathrm{n}$ - número da simulação realizada $(\mathrm{n}=1,2,3, \ldots)$

PV - preço de venda

CMD - custo de material direto

CMOD - custo de mão-de-obra direta

CDU - custo direto de utilidades (ex: energia direta)

DVU - despesas variáveis unitárias

IR - índice de rendimento

A expressão que define o Î́ndice de Rendimento é dada por:

$$
\mathrm{IR}=1-\left(\begin{array}{l}
\mathrm{nr} \\
\mathrm{np}
\end{array}\right)
$$

Onde: $\mathrm{nr}$ - número médio de produtos refugados por mês

$\mathrm{np}$ - número médio de produtos produzidos por mês

Para o cálculo do preço de venda, em cada simulação, faz-se:

$$
\mathrm{PV}_{\mathrm{n}}=\text { Cot.PV ALEATÓRIO } \mathrm{n}
$$

Onde: Cot.PV ALEATÓRIO $\mathrm{n}$ - valor cotado para o preço de venda relacionado com o número aleatório que incide no intervalo correspondente ao valor cotado e gerado na n-ésima simulação $\left(0<\mathrm{n}^{0}\right.$ aleatório $\left.<=1\right)$

Para o cálculo de cada custo unitário (CMD, CMOD ou CDU), em cada simulação, utiliza-se a expressão:

$$
\text { CUN }_{n}=\text { COUN ALEATÓRIO }_{n} \mathrm{x} \text { VURC }
$$
ou CDU)

Onde: CUN n - custo unitário do recurso na n-ésima simulação (CMD, CMOD

COUN ALEATÓRIO $\mathrm{n}$ - valor do consumo unitário de recurso (material direto, mão-de-obra direta ou utilidades) relacionado com o número aleatório gerado na nésima simulação

VURC - valor (custo) da unidade de recurso consumido

Para a determinação do valor da despesa variável unitária, em cada simulação, faz-se um cálculo similar ao apresentado na expressão 3 , como é mostrado a seguir:

$$
\text { DVU }_{\mathrm{n}}=\text { DVU ALEATÓRIO }_{\mathrm{n}}
$$


Onde: DVU $\mathrm{n}$ - despesa variável unitária

DVU ALEATÓRIO $\mathrm{n}$ - valor de despesa variável unitária relacionado com o número aleatório gerado na n-ésima simulação

Após a aplicação das simulações, a MCU esperada de cada produto é determinada para o período em análise. Para tal, projetam-se as MCU's apontadas em cada simulação na forma de uma função densidade de probabilidade para a aplicação de estatística descritiva. A estatística utilizada é a média das MCU's. Assim, para efeito deste estudo, o valor da MCU esperada de cada produto pode ser descrito pela expressão 6:

$$
\mathrm{MCU}_{\mathrm{E}}=\frac{\sum_{n=1}^{k} \mathrm{MCU}_{\mathrm{n}}}{\mathrm{k}}
$$

Onde: $k$ - número de simulações realizadas $(k>100)$

MCU E - Margem de Contribuição Unitária Esperada de cada tipo de produto

Para a realização das operações matemáticas anteriores, sugere-se o uso do software EXCEL ${ }^{2} 2007$, tanto por este possuir um recurso de geração de números aleatórios, como por ser de fácil acessibilidade. Vale destacar que as MCU's esperadas encontradas são métricas econômicas básicas para alicerçar a decisão de mix de produtos, aliadas à projeção da demanda, que será discutida na etapa seguinte.

\subsection{Etapa 4 - analisar e projetar demanda e necessidade de produção}

De modo similar ao das primeiras duas etapas, esta se inicia com um estudo analítico com base em dados históricos relativos à demanda pelos produtos da empresa. A demanda, normalmente, é constituída por pedidos em carteira somados a uma quantidade aleatória de solicitações dos clientes. Em alguns casos, são requeridos produtos para teste ou para exposição. Existem vários métodos e softwares que fazem projeção ou previsão de demanda a partir de dados históricos (ex: WINQSB $®$ ).

Para a definição da quantidade a ser produzida no período, deve-se levar em consideração o Índice de Rendimento, pois a empresa tem que produzir uma quantidade maior do que a demandada devido aos itens que são refugados, como mostra a expressão a seguir:

$$
\mathrm{QP}_{\mathrm{it}}=\frac{\mathrm{D}_{\mathrm{it}}}{\mathrm{IR}}
$$

Onde: QP i t - quantidade a ser produzida do produto i no período $t$

$\mathrm{D}$ i $\mathrm{t}$ - demanda do produto i no período $\mathrm{t}$

No presente estudo, utiliza-se a projeção de vendas para um único período, previsão esta que, aliada ao consumo unitário do recurso que restringe a capacidade do sistema, é aproveitada na decisão de mix de produtos. 


\subsection{Etapa 5 - verificar existência de recurso com restrição de capacidade e calcular a sua disponibilidade}

Nesta etapa é realizada uma análise de disponibilidade dos recursos produtivos da empresa, a saber: mão-de-obra, insumos e maquinário. No primeiro tipo de recurso, são incluídos os tempos de trabalho de todos os operários envolvidos com a fabricação dos produtos, tanto com a carga horária normal, como também as horas extras e subcontratações, para cada turno de trabalho. Ressaltase que o tempo de trabalho disponível dos trabalhadores é limitado de acordo com a legislação trabalhista vigente no país.

A disponibilidade de insumos é determinada pela capacidade de suprimento dos fornecedores da empresa. Neste item podemos abordar, também, a capacidade de fornecimento de utilidades que, normalmente, não oferecem restrições ao processo produtivo, mas podem ter custos proibitivos como no caso das taxas de energia elétrica cobradas em horários de pico. A determinação da disponibilidade do maquinário exige um conhecimento acerca de algumas características e peculiaridades inerentes ao processo produtivo, a saber: capacidade nominal de funcionamento das máquinas, paradas causadas por manutenção (programada e não programada), fatores externos (falta de água, vapor, energia, etc.), restabelecimento de condições operacionais (tempo de setup e reinício de produção), perdas por velocidade de operação, índice de refugos, entre outras. Vale ressaltar que o índice de refugo está relacionado com a qualidade do processo. Em outras palavras, é relativo à quantidade de produtos fabricados com alguma não conformidade em relação aos padrões de qualidade exigidos pelo cliente.

Os valores de capacidade para cada tipo de recurso devem ser confrontados para se determinar qual dos recursos é o RRC, caso realmente a restrição esteja no processo produtivo. O RRC apontado serve como base para a determinação de um critério ou métrica de priorização do mix de produtos para maximização do resultado econômico da empresa, métrica esta que é tratada na etapa seguinte.

\subsection{Etapa 6 - determinar a MCUE sobre o consumo esperado de RRC para cada produto}

O output desta etapa é uma métrica econômica para alicerçar a definição do mix de produtos. Esta métrica considera o valor da MCU esperada e o consumo esperado de RRC por unidade produzida de cada tipo de produto. Para tal, faz-se o uso das informações obtidas nas etapas três e cinco. A etapa três, além de fornecer as MCU's esperadas de cada tipo de produto, municia o estudo com informações relativas ao consumo, por produto e para cada simulação, do RRC determinado. $\mathrm{Na}$ quinta etapa, é levantado o recurso limitante do sistema produtivo.

Os consumos esperados de RRC para o período em apreciação são obtidos através de análise estatística do consolidado de todos os valores gerados em cada uma das simulações. Desta forma, os consumos resultantes de cada simulação podem ser projetados através de distribuições de frequência para, então, realizar-se a aferição da média de consumo de RRC de cada produto. Para tal, sugere-se o uso do software MINITAB ${ }^{\circ}$ 15.0, já que este tem a capacidade de exportar dados 
diretamente do software EXCEL® 2007. A métrica econômica é definida, para cada tipo de produto, como:

$$
\text { Métrica Econômica de Decisão de Mix Produtos }=\frac{\mathrm{MCU}_{\mathrm{E}}}{{\text { Consumo de } \mathrm{RRC}_{\mathrm{E}}}}
$$

A seguir, é discutida a determinação do mix de produtos com base na métrica econômica definida na corrente etapa.

\subsection{Etapa 7 - determinar mix de produtos com base na MCUE sobre o consumo de RRCE}

De posse do valor da métrica econômica definida na etapa anterior para cada produto e das previsões de demanda e de produção, obtidas na quarta etapa, o mix de produtos é determinado de forma a maximizar o resultado econômico da empresa. Em outras palavras, estabelece-se a prioridade de fabricação e venda dos produtos visando à consecução da maior Margem de Contribuição Total Esperada (MCTE) possível no período. Ressalta-se que a MCTE auferida deve ser capaz de cobrir custos e despesas fixas e ainda gerar lucro à empresa.

A sistemática de priorização é a seguinte: a demanda pelo tipo de produto que possui maior MCU esperada sobre o consumo de RRC é prioritariamente atendida. Quando numericamente a produção e venda de todos esses produtos é esgotada, passa-se a trabalhar com o tipo de produto com a segunda maior MCU esperada sobre consumo de RRC, e assim por diante. A produção é cessada na ocasião em que a capacidade de fornecimento da empresa verifica-se menor que a demanda.

\section{APLICAC̨̃̃O DO MÉTODO PROPOSTO}

Esta seção apresenta a aplicação do método proposto a partir de dados e informações coletados em uma indústria brasileira que atua na fabricação de produtos plásticos através do beneficiamento de material reciclado. Vale ressaltar que apenas dados referentes aos custos com matéria-prima, mão-de-obra direta e de energia direta, além dos tempos unitários de produção, são reais. Os demais dados utilizados foram gerados hipoteticamente, porém fidedignos à realidade do negócio. Com isso, buscou-se a organização de um cenário empresarial, balizado por suposições, correspondente ao da indústria em análise para a aplicação do método. 
Com mais de 30 anos de existência no mercado, a empresa trabalha com máquinas de injeção e de sopro para fabricar artigos variados como baldes, mesas, cadeiras, dentre outros produtos. Uma pesquisa divulgada pela Associação Brasileira da Indústria do Plástico (ABIPLAST) revelou que, em 2008, o setor de transformação de plásticos, setor este na qual está inserida a indústria em questão, foi responsável pela geração de 314 mil empregos e apresentou um faturamento de cerca de 41 bilhões de reais, o que mostra a relevância deste setor para a economia do país (ABIPLAST, 2008). Em um boletim informativo divulgado pelo Compromisso Empresarial para Reciclagem (CEMPRE), foi afirmado que é possível economizar até $50 \%$ de energia com o uso de plástico reciclado (CEMPRE, 2002). Este fato aliado ao baixo custo de coleta desse material devido à baixa remuneração dos chamados "catadores", faz com que o custo desse material seja menor que o custo do plástico "virgem". Em contrapartida, a qualidade do primeiro tipo de plástico é inferior à do segundo, principalmente, no que diz respeito à resistência a esforços mecânicos e à uniformidade de processamento.

Uma menor resistência a esforços mecânicos têm impactos negativos sobre a qualidade dos produtos (ex: índices de refugo maiores), enquanto que uma menor uniformidade do processo produtivo acarreta em variabilidade no consumo de recursos produtivos (ex: material direto; e tempo de mão-de-obra e de energia elétrica) e, conseqüentemente, nos custos destes.

\subsection{Definição do problema}

Para efeito do corrente estudo, conjecturou-se que os gestores da fabricante de artefatos plásticos em questão necessitavam estabelecer um mix de produtos tendo em vista que a capacidade produtiva da empresa (tempo de processamento das máquinas de injeção) não seria capaz de suprir a demanda em um determinado mês do ano de 2007. Para tal, aplicou-se o método proposto na seção 4, considerando que os produtos da empresa apresentavam acentuada variabilidade de consumo de recursos e, consequentemente, de custos unitários. Vale ressaltar que o estudo aborda uma situação hipotética em que são estabelecidas algumas suposições sobre o tipo de negócio e sobre processo produtivo da empresa em questão, suposições estas que balizam o cenário empresarial criado para a aplicação do método proposto de forma a evitar possíveis distorções na análise. As suposições mais relevantes são destacadas a seguir:

$>$ Para o mês de outubro de 2007, prevê-se que a demanda ultrapassa a capacidade de fornecimento da empresa em termos de tempo de processamento das máquinas de injeção de plástico;

$>$ A empresa possui restrições de capital para investir em novas máquinas de injeção para ampliar a capacidade produtiva;

$>$ Os preços de venda praticados pela empresa são tabelados e negociáveis;

$>$ A empresa produz oito tipos de produtos utilizando material reciclado 
em sete máquinas de injeção com características distintas;

$>$ Todas as máquinas podem produzir qualquer tipo de produto mediante troca de molde/ferramenta;

$>$ Não se considera a indisponibilidade de produção causada por fatores externos, matéria-prima e mão-de-obra.

> Todos os operadores têm a mesma habilidade de operação, sabendo operar em qualquer máquina;

$>$ Os tempos de preparação de máquina ou de setup independem da seqüência de produção e são iguais para todos os tipos de molde;

$>$ Apenas dois setups mensais são realizados para fabricação de cada tipo de produto;

$>$ As comissões sobre vendas aumentam conforme o preço de venda aplicado;

$>$ A empresa realiza a entrega dos produtos para os clientes.

\subsection{Aplicação do método proposto}

Em cada etapa do método, são trabalhados dados relativos à empresa em questão. Os dados da primeira etapa, relativos aos consumos de recursos e aos custos unitários de cada produto, são reais. Já a base de dados das demais etapas é fictícia, porém, tem correspondência verossímil com o tipo de processo produtivo da empresa. Com o intuito de reduzir o excesso de informações desta seção, tomouse como base informações referentes a um dos produtos fabricados, o produto "Balde para Construção" (BCON).

\subsubsection{Etapa 1 - analisar e projetar gastos unitários}

Para realizar esta etapa, primeiramente, realizou-se um levantamento dos produtos fabricados pela empresa e a composição de cada um deles, como mostra o quadro 2:

\begin{tabular}{|c|c|c|c|c|c|}
\hline \multirow{2}{*}{ TIPO DE PRODUTO } & \multirow{2}{*}{$\begin{array}{c}\text { CÓDIGO } \\
\text { MNEMÔNICO }\end{array}$} & \multicolumn{4}{|c|}{ COMPOSIÇÃO } \\
\cline { 3 - 6 } & & MATERIAL 1: PLÁSTICO & \multicolumn{2}{c|}{ MATERIAL 2: ALÇA METÁLICA } \\
\cline { 3 - 6 } & & BESCRIÇÃO & QDE (Kg) & DESCRIÇÃO & QDE (Kg) \\
\hline BALDE 8L & BD10L & B/B COLOR. REC. & (VARIÁ VEL) & AÇO GALV. 3,4 mm & 0,035 \\
\hline BALDE 10L & BD15L & B/B COLOR. REC. & (VARIÁ VEL) & AÇO GALV. 3,4 mm & 0,040 \\
\hline BALDE 15L & BD20L & B/B COLOR. REC. & (VARIÁ VEL) & AÇO GALV. 4,0 mm & 0,061 \\
\hline BALDE 20L & BC45L & B/B COLOR. REC. & (VARIÁ VEL) & - & - \\
\hline BACIA 45L & BC73L & CAD COLOR. REC. & (VARIÁ VEL) & - & - \\
\hline BACIA 73L & CLX & B/B COLOR. REC. & (VARIÁ VEL) & - & - \\
\hline CESTO DE LIXO & BCON & B/BPRETO REC. & (VARIÁ VEL) & AÇO GALV. 4,0 mm & 0,057 \\
\hline BALDE PARA CONSTRUÇÃO & &
\end{tabular}

Quadro 2 - Relação de produtos fabricados e materiais componentes 
Como a empresa utiliza plástico reciclado como matéria-prima, dependendo da qualidade desta, há variabilidade no consumo de material e no tempo de fabricação de cada produto no decorrer do ano. Com isso, fez-se um levantamento histórico dos nove meses anteriores ao período de análise, do gasto de MP. Os gastos foram segmentados ao máximo, com o intuito de se identificar o quanto cada um representa em cada um dos itens produzidos, obtendo assim, uma visão geral dos gastos envolvidos com o negócio. Para efeito do estudo em curso, analisou-se apenas a variação dos gastos unitários, variação esta que foi projetada na forma de distribuições de freqüência para ser trabalhada através de simulação. O quadro 3 , referente ao produto BCON, apresenta o histórico de consumo de MP. Vale ressaltar que o levantamento foi realizado através de amostras de cinco produtos coletadas a cada lote de cem unidades fabricadas e que os dados foram projetados na forma de distribuição de freqüência.

\begin{tabular}{|c|c|c|c|c|c|c|c|c|c|c|c|c|c|}
\hline \multirow{2}{*}{$\begin{array}{c}\text { MÉDIA AMOSTRAL DE } \\
\text { CONSUMO DE B/B PRETO. } \\
\text { REC.(Kg) }\end{array}$} & \multicolumn{9}{|c|}{ FREQÜÊNCIA ABSOLUTA DE CONSUMO EM 2007 - BALDE P/ CONSTRUÇÃO } & \multicolumn{4}{|c|}{ CONSOLIDADO (JAN. À SET.) - BALDEP/ CONSTRUÇÃO } \\
\hline & JAN & FEV & MAR & ABR & MAI & JUN & JUL & AGO & SET & $\begin{array}{c}\text { CONSUMO DE B/B PRETO. } \\
\text { REC.(Kg) }\end{array}$ & $\begin{array}{l}\text { FREQÜÊNCIA } \\
\text { ABSOLUTA }\end{array}$ & $\begin{array}{l}\text { FREQUÊNCIA } \\
\text { RELATIVA }\end{array}$ & $\begin{array}{l}\text { FREQUÊNCIA } \\
\text { ACUMULADA }\end{array}$ \\
\hline 0,630 & 200 & 100 & 100 & 200 & 400 & - & 400 & 400 & 300 & 0,630 & 2.100 & $0,52 \%$ & $0,52 \%$ \\
\hline 0,631 & 300 & 100 & - & 100 & 900 & - & 600 & 500 & 800 & 0,631 & 3.300 & $0,82 \%$ & $1,34 \%$ \\
\hline 0,632 & 600 & 300 & 200 & 300 & 1.700 & - & 800 & 800 & 1.300 & 0,632 & 6.000 & $1,49 \%$ & $2,83 \%$ \\
\hline 0,633 & 500 & 500 & 400 & 500 & 2.300 & - & 1.500 & 1.200 & 1.800 & 0,633 & 8.700 & $2,16 \%$ & $4,98 \%$ \\
\hline 0,634 & 900 & 400 & 700 & 700 & 3.200 & 100 & 2.100 & 1.800 & 2.500 & 0,634 & 12.400 & $3,07 \%$ & $8,06 \%$ \\
\hline 0,635 & 1.300 & 900 & 700 & 900 & 3.900 & 500 & 2.800 & 2.400 & 3.900 & 0,635 & 17.300 & $4,29 \%$ & $12,34 \%$ \\
\hline 0,636 & 1.900 & 1.600 & 1.100 & 1.300 & 3.300 & 200 & 3.500 & 3.200 & 5.800 & 0,636 & 21.900 & $5,43 \%$ & $17,77 \%$ \\
\hline 0,637 & 2.600 & 2.300 & 1.500 & 1.600 & 3.100 & 100 & 4.200 & 4.074 & 5.000 & 0,637 & 24.474 & $6,07 \%$ & $23,84 \%$ \\
\hline 0,638 & 3.000 & 3.100 & 1.600 & 1.900 & 2.995 & 600 & 5.100 & 3.900 & 4.800 & 0,638 & 26.995 & $6,69 \%$ & $30,53 \%$ \\
\hline 0,639 & 3.700 & 3.900 & 1.500 & 2.100 & 2.500 & 400 & 4.500 & 3.500 & 4.300 & 0,639 & 26.400 & $6,54 \%$ & $37,07 \%$ \\
\hline 0,640 & 4.500 & 4.700 & 2.100 & 2.600 & 2.100 & 900 & 3.800 & 2.900 & 3.600 & 0,640 & 27.200 & $6,74 \%$ & $43,82 \%$ \\
\hline 0,641 & 5.200 & 4.200 & 2.400 & 2.900 & 1.800 & 1.200 & 3.500 & 3.200 & 3.985 & 0,641 & 28.385 & $7,04 \%$ & $50,85 \%$ \\
\hline 0,642 & 4.600 & 3.900 & 2.889 & 3.400 & 1.700 & 1.400 & 3.000 & 2.500 & 2.800 & 0,642 & 26.189 & $6,49 \%$ & $57,34 \%$ \\
\hline 0,643 & 4.000 & 3.600 & 3.100 & 3.836 & 1.500 & 900 & 2.400 & 2.600 & 2.700 & 0,643 & 24.636 & $6,11 \%$ & $63,45 \%$ \\
\hline 0,644 & 3.200 & 3.700 & 3.500 & 3.700 & 1.400 & 1.600 & 1.800 & 2.400 & 2.500 & 0,644 & 23.800 & $5,90 \%$ & $69,35 \%$ \\
\hline 0,645 & 2.700 & 2.900 & 3.800 & 3.600 & 1.200 & 1.900 & 1.460 & 2.100 & 2.200 & 0,645 & 21.860 & $5,42 \%$ & $74,77 \%$ \\
\hline 0,646 & 1.500 & 2.000 & 4.200 & 3.000 & 800 & 2.300 & 900 & 1.800 & 2.200 & 0,646 & 18.700 & $4,64 \%$ & $79,40 \%$ \\
\hline 0,647 & 1.400 & 1.494 & 4.400 & 2.600 & 500 & 2.000 & 500 & 1.500 & 2.000 & 0,647 & 16.394 & $4,06 \%$ & $83,47 \%$ \\
\hline 0,648 & 1.300 & 1.300 & 3.900 & 2.100 & 600 & 3.200 & 300 & 1.000 & 1.800 & 0,648 & 15.500 & $3,84 \%$ & $87,31 \%$ \\
\hline 0,649 & 700 & 1.300 & 3.600 & 1.500 & 300 & 3.800 & 200 & 700 & 1.300 & 0,649 & 13.400 & $3,32 \%$ & $90,63 \%$ \\
\hline 0,650 & 600 & 600 & 2.900 & 800 & 200 & 4.300 & - & 400 & 1.700 & 0,650 & 11.500 & $2,85 \%$ & $93,48 \%$ \\
\hline 0,651 & 800 & 800 & 1.500 & 400 & - & 4.400 & 100 & 300 & 1.800 & 0,651 & 10.100 & $2,50 \%$ & $95,98 \%$ \\
\hline 0,652 & 698 & 500 & 1.100 & 200 & 100 & 3.500 & 200 & - & 1.300 & 0,652 & 7.598 & $1,88 \%$ & $97,87 \%$ \\
\hline 0,653 & 300 & 300 & 900 & - & - & 2.400 & - & 100 & 900 & 0,653 & 4.900 & $1,21 \%$ & $99,08 \%$ \\
\hline 0,654 & 100 & 100 & 500 & 100 & - & 1.300 & - & - & 500 & 0,654 & 2.600 & $0,64 \%$ & $99,73 \%$ \\
\hline 0,655 & - & 200 & 200 & - & - & 500 & - & - & 200 & 0,655 & 1.100 & $0,27 \%$ & $100,00 \%$ \\
\hline TOTAL & 46.598 & 44.794 & 48.789 & 40.336 & 36.495 & 37.500 & 43.660 & 43.274 & 61.985 & SOMA & 403.431 & $100 \%$ & \\
\hline
\end{tabular}

Em seguida, foram coletadas informações referentes aos preços de aquisição dos materiais para determinar os custos por quilograma de consumo. Vale ressaltar que há produtos formados por mais de um componente, como o produto BCON. De cada componente, são retirados os impostos sobre compra de matéria-prima, sendo estes recuperados posteriormente na venda. Assim, calculou-se o custo de material por produto ou componente, como mostra o quadro 4. Ressalta-se que o custo do material é alocado diretamente no cálculo do gasto unitário de cada produto.

\begin{tabular}{|c|c|c|c|c|}
\hline MATÉRIA-PRIMA & PREÇO / Kg & ICMS & IPI & CUSTO / Kg \\
\hline AÇO GALVANIZADO 3,4 mm & $\mathrm{R} \$ 2,94$ & $\mathrm{R} \$ 0,336$ & $\mathrm{R} \$ 0,14$ & $\mathrm{R} \$ 2,464$ \\
\hline AÇO GALVANIZADO 4,0 mm & $\mathrm{R} \$ 2,94$ & $\mathrm{R} \$ 0,336$ & $\mathrm{R} \$ 0,14$ & $\mathrm{R} \$ 2,464$ \\
\hline PLÁSTICO B/B COLORIDO RECICLADO & $\mathrm{R} \$ 1,66$ & - & - & $\mathrm{R} \$ 1,66$ \\
\hline PLÁSTICO B/B PRETO RECICLADO & $\mathrm{R} \$ 1,62$ & - & - & $\mathrm{R} \$ 1,62$ \\
\hline PLÁSTICO CAD COLORIDO RECICLADO & $\mathrm{R} \$ 2,56$ & - & - & $\mathrm{R} \$ 2,56$ \\
\hline
\end{tabular}

Quadro 4 - Custo por quilograma de matéria-prima consumida 
Para a determinação dos custos unitários de mão-de-obra direta foi realizado um procedimento similar ao utilizado na determinação dos custos unitários anteriores. Como os custos unitários de MOD relacionam-se diretamente com o tempo despendido pelos operários em cada produto e que, no caso da empresa em questão, este tempo está limitado à duração do processamento de cada unidade, foi feito um levantamento histórico dos Tempos de Ciclo (TC) no horizonte de nove meses. Para este levantamento, fez-se o uso de amostras de cinco produtos coletadas a cada lote de cem unidades fabricadas. Os tempos foram medidos e disponibilizados pelas máquinas injetoras que dispunham de medidores internos. 0 quadro 5 apresenta o levantamento realizado para o produto BCON. Os dados levantados foram projetados na forma de distribuição de freqüência.

\begin{tabular}{|c|c|c|c|c|c|c|c|c|c|c|c|c|c|}
\hline \multirow[b]{2}{*}{$\begin{array}{l}\text { TEMPO DE CICLO } \\
\text { (segundos) }\end{array}$} & \multicolumn{9}{|c|}{ FREQÜËNCIA ABSOLUTA DE TEMPO DE CICLO EM 2007 - BALDE P/ CONSTRUÇÃO } & \multicolumn{4}{|c|}{ CONSOLIDADO (JAN. À SET.) - BALDEP/ CONSTRUÇÃO } \\
\hline & JAN & FEV & MAR & $\mathrm{ABR}$ & MAI & JUN & JUL & AGO & SET & $\begin{array}{l}\text { TEMPO DE CICLO } \\
\text { (segundos) }\end{array}$ & $\begin{array}{c}\text { FREQÜÊNCIA } \\
\text { ABSOLUTA }\end{array}$ & $\begin{array}{l}\text { FREQUÊNCIA } \\
\text { RELATIVA }\end{array}$ & $\begin{array}{r}\text { FREQUÊNCIA } \\
\text { ACUMULADA }\end{array}$ \\
\hline 24 & 300 & 200 & - & 200 & - & - & - & - & 400 & 24 & 1.100 & $0,27 \%$ & $0,27 \%$ \\
\hline 25 & 900 & 400 & 700 & 500 & 200 & - & - & - & 1.200 & 25 & 3.900 & $0,97 \%$ & $1,24 \%$ \\
\hline 26 & 1.800 & 900 & 1.100 & 900 & 300 & - & - & - & 2.100 & 26 & 7.100 & $1,76 \%$ & $3,00 \%$ \\
\hline 27 & 2.900 & 1.600 & 1.500 & 1.300 & 400 & - & - & 100 & 3.100 & 27 & 10.900 & $2,70 \%$ & $5,70 \%$ \\
\hline 28 & 3.800 & 2.300 & 2.200 & 1.700 & 800 & - & - & 300 & 4.200 & 28 & 15.300 & $3,79 \%$ & $9,49 \%$ \\
\hline 29 & 5.100 & 3.300 & 2.900 & 1.900 & 1.300 & 300 & 200 & 500 & 5.800 & 29 & 21.300 & $5,28 \%$ & $14,77 \%$ \\
\hline 30 & 6.498 & 3.900 & 3.700 & 2.100 & 1.700 & 100 & 100 & 700 & 5.600 & 30 & 24.398 & $6,05 \%$ & $20,82 \%$ \\
\hline 31 & 5.300 & 4.794 & 4.600 & 2.600 & 2.600 & 500 & 400 & 900 & 5.200 & 31 & 26.894 & $6,67 \%$ & $27,49 \%$ \\
\hline 32 & 4.700 & 4.200 & 5.800 & 2.900 & 3.400 & 400 & 800 & 1.100 & 4.900 & 32 & 28.200 & $6,99 \%$ & $34,48 \%$ \\
\hline 33 & 4.000 & 3.900 & 4.900 & 3.400 & 4.100 & 900 & 1.000 & 1.300 & 4.200 & 33 & 27.700 & $6,87 \%$ & $41,34 \%$ \\
\hline 34 & 3.200 & 3.600 & 4.100 & 3.900 & 3.795 & 1.200 & 1.600 & 1.700 & 3.900 & 34 & 26.995 & $6,69 \%$ & $48,03 \%$ \\
\hline 35 & 2.700 & 3.700 & 3.889 & 3.700 & 3.400 & 1.400 & 2.400 & 2.200 & 2.885 & 35 & 26.274 & $6,51 \%$ & $54,55 \%$ \\
\hline 36 & 1.500 & 2.900 & 3.500 & 3.600 & 3.000 & 1.700 & 2.800 & 2.900 & 3.200 & 36 & 25.100 & $6,22 \%$ & $60,77 \%$ \\
\hline 37 & 1.400 & 2.400 & 3.000 & 3.000 & 2.700 & 1.600 & 3.500 & 3.500 & 2.900 & 37 & 24.000 & $5,95 \%$ & $66,72 \%$ \\
\hline 38 & 900 & 2.100 & 2.400 & 2.600 & 2.100 & 1.900 & 4.200 & 4.400 & 2.500 & 38 & 23.100 & $5,73 \%$ & $72,44 \%$ \\
\hline 39 & 700 & 2.600 & 1.800 & 2.100 & 1.900 & 2.300 & 5.100 & 3.900 & 1.900 & 39 & 22.300 & $5,53 \%$ & $77,97 \%$ \\
\hline 40 & 600 & 900 & 1.100 & 1.536 & 1.700 & 2.000 & 4.500 & 3.574 & 2.100 & 40 & 18.010 & $4,46 \%$ & $82,44 \%$ \\
\hline 41 & 300 & 600 & 800 & 1.100 & 1.400 & 3.200 & 3.800 & 3.300 & 1.800 & 41 & 16.300 & $4,04 \%$ & $86,48 \%$ \\
\hline 42 & - & 300 & 400 & 600 & 900 & 3.800 & 3.500 & 3.200 & 1.400 & 42 & 14.100 & $3,50 \%$ & $89,97 \%$ \\
\hline 43 & - & 200 & 300 & 300 & 500 & 4.300 & 3.260 & 2.800 & 1.100 & 43 & 12.760 & $3,16 \%$ & $93,13 \%$ \\
\hline 44 & - & - & - & 200 & 200 & 4.600 & 2.200 & 2.400 & 800 & 44 & 10.400 & $2,58 \%$ & $95,71 \%$ \\
\hline 45 & - & - & 100 & 200 & - & 3.500 & 1.800 & 2.100 & 400 & 45 & 8.100 & $2,01 \%$ & $97,72 \%$ \\
\hline 46 & - & - & - & - & 100 & 2.100 & 1.200 & 1.400 & 200 & 46 & 5.000 & $1,24 \%$ & $98,96 \%$ \\
\hline 47 & - & - & - & - & - & 1.200 & 900 & 700 & 100 & 47 & 2.900 & $0,72 \%$ & $99,68 \%$ \\
\hline 48 & - & - & - & - & - & 500 & 400 & 300 & 100 & 48 & 1.300 & $0,32 \%$ & $100,00 \%$ \\
\hline
\end{tabular}

\begin{tabular}{|l|l|l|l|l|l|l|l|l|l|l|l|l|}
\hline PRODUÇÃO TOTAL & 46.598 & 44.794 & 48.789 & 40.336 & 36.495 & 37.500 & 43.660 & 43.274 & 61.985 & SOMA & 403.431 & $100 \%$ \\
\hline
\end{tabular}

Quadro 5: Freqüência absoluta de tempo unitário de processamento do produto BCON

Para a determinação do custo da mão-de-obra diretamente envolvida com a fabricação dos produtos, foram analisados os seguintes gastos: salário nominal, adicional noturno, encargos sociais, férias, décimo terceiro salário, vale-transporte, vale-refeição e equipamentos de proteção individual. De posse desses dados, fez-se um consolidado por função, com seu gasto total. Em seguida, calculou-se o custo da mão-de-obra por hora e por segundo da função Auxiliar de Fabricação, função esta diretamente relacionada com a fabricação dos produtos. Para isso, analisou-se o somatório dos salários e encargos de cada funcionário e calculou-se a média mensal de custos de mão-de-obra direta. Posteriormente, para determinar o custo total de mão-de-obra direta, multiplicou-se o custo médio pela quantidade de Auxiliares de Fabricação existentes na fábrica. O valor total encontrado foi dividido pela carga horária mensal total de trabalho para a determinação do custo por hora. Finalmente, dividiu-se o custo por hora por 3600 para encontrar o custo de mão-de-obra direta por segundo de trabalho. O custo por segundo de MOD encontrado foi de R\$ 0,00101. O custo por segundo de MOD foi utilizado no cálculo do custo unitário de MOD de cada produto ou componente, valor que participa diretamente na determinação da MCU. O quadro 6 mostra o cálculo para os componentes dos produtos em estudo: 


\begin{tabular}{|c|c|c|c|c|}
\hline ITEM / PRODUTO & $\begin{array}{c}\text { TEMPO DE CICLO } \\
\text { (segundos) }\end{array}$ & $\begin{array}{c}\text { CUSTO / SEGUNDO } \\
\text { DE MOD }\end{array}$ & $\begin{array}{c}\text { NECESSIDADE DE } \\
\text { OPERÁRIOS P/ PRODUÇÃO }\end{array}$ & $\begin{array}{c}\text { CUSTO DE } \\
\text { MOD / ITEM }\end{array}$ \\
\hline ALÇA METÁLICA 3,4 mm / BD8L & 2,7 & 0,00101 & 1 & 0,002727 \\
\hline ALÇA METÁLICA 3,4 mm / BD10L & 2,7 & 0,00101 & 1 & 0,002727 \\
\hline ALÇA METÁLICA 3,4 mm / BD15L & 3,1 & 0,00101 & 1 & 0,003131 \\
\hline ALÇA METÁLICA 4,0 mm / BD20L & 8,0 & 0,00101 & 1 & 0,00808 \\
\hline ALÇA METÁLICA 4,0 mm / BCON & 8,0 & 0,00101 & 1 & 0,00808 \\
\hline
\end{tabular}

Quadro 6 - Custo de MOD para cada componente dos produtos

Para a determinação dos custos relacionados com a energia diretamente consumida pelas máquinas do setor produtivo, foi feito um levantamento histórico dos gastos totais com energia na empresa. Em seguida, foi verificado que uma parte do consumo energético não se relacionava diretamente à fabricação dos produtos, como no caso da iluminação, computadores, ar-condicionado, entre outros. Assim, foi retirado da conta de energia total da empresa, desconsiderando os impostos, apenas o que foi consumido diretamente no processo produtivo, considerando 0 restante como consumo indireto. O valor encontrado foi de $R \$ 0,19551$ por $\mathrm{kWh}$.

Para encontrar o valor do consumo energético de cada máquina diretamente relacionada com a fabricação dos produtos, foram realizadas mensurações a partir de medidores eletrônicos e observações nos manuais dos fabricantes. Os valores encontrados foram multiplicados pelo custo por kWh previamente calculado, o que resultou no custo de energia por hora de operação de cada máquina. Por motivo de adequação à unidade de tempo utilizada no corrente estudo, o segundo, dividiu-se os valores encontrados por 3600. Das máquinas utilizadas na produção, verificou-se que a ALÇA 1 operava apenas na fabricação das alças metálicas de $3,4 \mathrm{~mm}$, enquanto que a máquina ALÇA 2 fabricava somente as alças de $4,0 \mathrm{~mm}$. O produto BCON poderia ser fabricado em qualquer uma das sete máquinas dos modelos INJ $A B$, INJ MN e INJ XY. Assim, de posse da quantidade existente de cada modelo e considerando que o tempo de ciclo não era afetado pela máquina escolhida para a produção, foram projetadas as probabilidades de cada uma das máquinas serem selecionadas para produzir um produto através de distribuição de freqüência, como mostra o quadro 7:

\begin{tabular}{|c|c|c|c|c|c|c|}
\hline MÁQUINA & $\begin{array}{l}\text { CONSUMO DE } \\
\text { ENERGIA (KWh) }\end{array}$ & $\begin{array}{l}\text { CUSTO / } \\
\text { KWh }\end{array}$ & $\begin{array}{l}\text { CUSTO DE ENERGIA / } \\
\text { HORA-MÁQUINA }\end{array}$ & \begin{tabular}{|c|} 
CUSTO DE ENERGIA / SEG.- \\
MÁQUINA
\end{tabular} & \multirow{3}{*}{$\begin{array}{l}\text { FREQÜÊNCIA } \\
\text { RELATIVA }\end{array}$} & \multirow{3}{*}{$\begin{array}{l}\text { FREQÜÊNCIA } \\
\text { ACUMULADA }\end{array}$} \\
\hline ALÇA 01 & 3,04 & 0,19551 & 0,5943504 & 0,00016510 & & \\
\hline ALÇA 02 & 1,52 & 0,19551 & 0,2971752 & 0,00008255 & & \\
\hline INJ AB 01 & 34,20 & 0,19551 & 6,686442 & \multirow{2}{*}{0,00185735} & \multirow{2}{*}{$40 \%$} & \multirow{2}{*}{$40 \%$} \\
\hline INJ AB 02 & 34,20 & 0,19551 & 6,686442 & & & \\
\hline INJ MN 01 & 30,40 & 0,19551 & 5,943504 & 0,00165097 & $20 \%$ & $60 \%$ \\
\hline INJ XY 01 & 32,30 & 0,19551 & 6,314973 & \multirow{2}{*}{0,00175416} & \multirow{2}{*}{$40 \%$} & \multirow{2}{*}{$100 \%$} \\
\hline INJ XY 02 & 32,30 & 0,19551 & 6,314973 & & & \\
\hline & & & & TOTAL & $100 \%$ & \\
\hline
\end{tabular}

Quadro 7 - Custo de energia por segundo de utilização das máquinas e probabilidade de seleção para produção

As despesas variáveis consideradas pela empresa em estudo são referentes aos gastos com comissão sobre vendas e com a entrega de cada produto. Verificouse que a alíquota da comissão do vendedor incidente sobre o preço de venda praticado era variável e tabelada. Quanto maior a cotação do preço, maior a alíquota da comissão. Desta forma, os vendedores eram motivados a vender os produtos pelos maiores preços possíveis. Pelo fato de a empresa realizar a distribuição dos produtos para lojas de atacado e de varejo a partir de uma frota própria de veículos, as despesas relacionadas com a entrega dos produtos foram determinadas para cada produto. Para tal, foram analisados os gastos relacionados com pneus utilizados, combustível, diárias dos motoristas e ajudantes, entre outros. Esses 
gastos foram considerados como despesas variáveis, sendo influenciados pelo volume de venda dos produtos. Para a determinação da despesa variável unitária de entrega de cada tipo de produto, fez-se o uso de dados históricos relativos ao total gasto com os itens acima citados e de informações a respeito da área ocupada por cada tipo de produto no compartimento de carga dos veículos. Vale ressaltar que os valores cotados são aproximados. O quadro 8 apresenta as alíquotas de comissão de vendas os valores de despesa de entrega:

\begin{tabular}{|c|c|c|c|}
\hline COTAÇÃO DO PREÇO & COMISSÃO SOBRE O PREÇO DE VENDA & PRODUTO & DESPESA VARIÁVEL DE ENTREGA \\
\hline \multirow{2}{*}{ P1 } & \multirow{2}{*}{$0,4 \%$} & BD8L & $\mathrm{R} \$ 0,0434$ \\
\hline & & BD10L & $\mathrm{R} \$ 0,0443$ \\
\hline \multirow{2}{*}{ P2 } & \multirow{2}{*}{$0,6 \%$} & BD15L & $\mathrm{R} \$ 0,0586$ \\
\hline & & BD20L & $\mathrm{R} \$ 0,0703$ \\
\hline \multirow{2}{*}{ Р3 } & \multirow{2}{*}{$0,8 \%$} & BC45L & $\mathrm{R} \$ 0,0712$ \\
\hline & & BC73L & $\mathrm{R} \$ 0,1184$ \\
\hline \multirow{2}{*}{ P4 } & \multirow{2}{*}{$1,0 \%$} & CLX & $\mathrm{R} \$ 0,0665$ \\
\hline & & BCON & $\mathrm{R} \$ 0,0649$ \\
\hline
\end{tabular}

As informações obtidas nesta etapa, aliadas à projeção das receitas unitárias de vendas (seção seguinte), foram utilizadas diretamente na determinação da MCU de cada produto.

\subsubsection{Etapa 2 - analisar e projetar receitas unitárias}

Após levantamento junto ao Setor Comercial da empresa, verificou-se que a precificação era realizada de forma tabelada. Para cada produto era utilizada uma tabela com quatro cotações de preço (do menor para o maior): P1, P2, P3 e P4. De acordo como poder de barganha do cliente, o vendedor estava autorizado a oferecer um desconto até o valor mínimo de P1. De posse dos preços praticados para a venda de cada produto, um estudo histórico foi realizado para determinar a freqüência de incidência de cada uma das cotações, como apresenta o quadro 9 aplicado ao produto BCON.

\begin{tabular}{|c|c|c|c|}
\hline \multicolumn{4}{|c|}{ BALDE PARA CONSTRUÇÃO } \\
\hline COTAÇÃO & PREÇO DE VENDA & FREQÜÊNCIA RELATIVA & FREQÜÊNCIA ACUMULADA \\
\hline P1 & $\mathrm{R} \$ 3,70$ & $15 \%$ & $15 \%$ \\
\hline P2 & $\mathrm{R} \$ 3,80$ & $25 \%$ & $40 \%$ \\
\hline P3 & $\mathrm{R} \$ 3,90$ & $40 \%$ & $80 \%$ \\
\hline P4 & $\mathrm{R} \$ 4,00$ & $20 \%$ & $100 \%$ \\
\hline \multicolumn{4}{|c|}{} \\
\hline
\end{tabular}

Quadro 9 - Preços praticados na venda do produto BCON com a incidência histórica de cada cotação

Os valores e as distribuições de freqüências encontradas, aliados à simulação de Monte Carlo, foram utilizados na determinação da MCU esperada para o mês de outubro de 2007 de cada produto. O cálculo da MCU esperada é abordado na etapa a seguir. 


\subsubsection{Etapa 3 - aplicar simulação e determinar a margem de contribuição unitária esperada de cada produto}

De posse dos custos por unidade de recursos produtivos (matéria-prima, mão-de-obra e energia elétrica) diretamente consumidos, dos preços de venda praticados, das despesas variáveis unitárias e das distribuições de freqüência dos consumos unitários de recursos e das cotações de preço por produto, determinou-se a Margem de Contribuição Unitária Esperada para o mês de outubro de 2007 para cada tipo de produto. Para tal, fez-se o uso do método de simulação de Monte Carlo com a geração de números aleatórios que incidiram sobre as distribuições de freqüência determinadas para cada consumo de recurso, despesa variável e cotação de preço de venda.

A utilização da simulação de Monte Carlo para determinação da MCUE deuse da seguinte forma: geraram-se números aleatórios não-nulo entre 0 e 1 e os remeteram, com base nas distribuições de freqüência estabelecidas, a um valor correspondente de consumo de matéria-prima, tempo de ciclo, custo energético por segundo de operação de máquina e preço de venda cotado. As distribuições de freqüência relativa apontaram as probabilidades de ocorrência de cada valor. As distribuições de freqüência absoluta serviram como base para a definição dos intervalos, entre 0 e 1, que se relacionavam aos números aleatórios gerados. Este procedimento foi replicado 10.000 vezes para a consecução de uma amostra representativa da realidade empresarial modelada. O quadro 10 apresenta uma aplicação de três simulações para o mesmo produto, seguindo as expressões 3, 4 e 5 apresentadas na seção 4.3.

\begin{tabular}{|c|c|c|c|c|c|c|c|c|}
\hline $\begin{array}{c}\mathrm{N}^{\circ} \\
\text { SIMULAÇÃOO }\end{array}$ & $\begin{array}{c}\text { NÚMERO } \\
\text { ALEATÓRIO }\end{array}$ & $\begin{array}{c}\text { CONSUMO B/B } \\
\text { PRETO. REC. (Kg) }\end{array}$ & $\begin{array}{c}\text { NÚMERO } \\
\text { ALEATÓRIO }\end{array}$ & $\begin{array}{c}\text { TEMPO DE } \\
\text { CICLO (seg.) }\end{array}$ & $\begin{array}{c}\text { NÚMERO } \\
\text { ALEATÓRIO }\end{array}$ & $\begin{array}{c}\text { CUSTO DE ENERGIA / } \\
\text { seg. MÁQUINA }\end{array}$ & $\begin{array}{c}\text { NÚMERO } \\
\text { ALEA TÓRIO }\end{array}$ & $\begin{array}{c}\text { RECEITA } \\
\text { UNITÁRIA }\end{array}$ \\
\hline 1 & 0,543 & 0,642 & 0,152 & 30 & 0,874 & 0,001754159 & 0,446 & 3,90 \\
\hline 2 & 0,321 & 0,639 & 0,946 & 44 & 0,121 & 0,001857345 & 0,479 & 3,90 \\
\hline 3 & 0,682 & 0,644 & 0,537 & 35 & 0,697 & 0,001754159 & 0,281 & 3,80 \\
\hline
\end{tabular}

Os valores encontrados relativos ao consumo unitário de matéria-prima foram multiplicados, em cada simulação, pelo custo por quilograma do material plástico utilizados em cada tipo de produto. Assim, conseguiu-se determinar o custo de material direto de cada produto fabricado, em cada simulação. Os tempos de ciclo encontrados foram multiplicados pelo custo de mão-de-obra direta por segundo de trabalho e pelo custo de energia por segundo de operação de máquina para a determinação do custo de MOD e da energia direta de cada tipo de produto, respectivamente. O somatório dos três custos unitários calculados foi dividido pelo Índice de Rendimento, como sugere a expressão 2. Para o cálculo do IR, foi realizado um levantamento histórico da quantidade total produzida (3.397.223 produtos) nos nove meses anteriores ao período em analise. Em seguida, levantouse o número total de unidades produzidas que não atenderam às necessidades dos clientes, expressas através de especificações de projeto (101.905 produtos). Desta forma, obteve-se um IR de 0,97. Assim, em cada simulação, a soma dos custos diretos de MP, de MOD e de energia foi dividida pelo valor do IR calculado, o que inflacionou, levemente, o valor dos custos unitário de cada produto. Esse valor adicionado ao custo unitário direto representa os gastos incorridos na fabricação dos produtos não-conformes. 
Os custos determinados em cada simulação, inflacionados pelo IR, foram somados aos custos unitários relacionados com a fabricação dos componentes (alça metálica). Vale destacar que esta soma foi aplicada, exclusivamente, aos produtos BCON, BD8L, BD10L, BD15L e BD20L. Finalmente, para o cálculo do gasto total unitário de cada produto, o valor da soma anterior foi adicionado ao valor das despesas variáveis unitárias. Tomando como base a expressão 1 do método proposto, os valores de gasto total unitário foram confrontados com as receitas unitárias para a determinação, em cada simulação, das MCU's dos produtos. $O$ quadro 11 apresenta, para o produto BCON, as MCU's obtidas com as 30 primeiras simulações. Ressalta-se que as simulações realizadas foram executadas no software EXCEL ${ }^{\circledR}$ 2007. Os números aleatórios gerados não aparecem no quadro 11, pois estes foram inseridos diretamente nas fórmulas de cálculo de cada item, quando aplicável.

\begin{tabular}{|c|c|c|c|c|c|c|c|c|c|c|c|c|c|c|c|}
\hline \multicolumn{16}{|c|}{ DETERMINAÇÃO DA MCU - BALDE PARA CONSTRUÇÃO } \\
\hline SIMULAÇÃO & $\begin{array}{c}\text { CONSUMO } \\
\text { B/B PRETO. } \\
\text { REC. (Kg) }\end{array}$ & 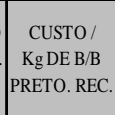 & $\begin{array}{c}\text { TEMPO DE } \\
\text { CICLO } \\
\text { (seg.) }\end{array}$ & $\begin{array}{l}\text { CUSTO / } \\
\text { seg. DE } \\
\text { MOD }\end{array}$ & $\begin{array}{l}\text { CUSTO DE } \\
\text { ENERGIA / } \\
\text { seg. } \\
\text { MÁQUINA }\end{array}$ & \begin{tabular}{|c|} 
CONSUMO \\
AÇO \\
GALV. 4,0 \\
$\mathrm{~mm}(\mathrm{Kg})$
\end{tabular} & $\begin{array}{l}\text { CUSTO / } \\
\text { Kg AÇO } \\
\text { GALV. } \\
4,0 \mathrm{~mm}\end{array}$ & $\begin{array}{c}\text { TEMPO DE } \\
\text { CICLO (seg.) } \\
\text { ALÇA } \\
\text { METÁLICA }\end{array}$ & \begin{tabular}{|c|} 
CUSTO \\
DE MOD \\
/ ALÇA
\end{tabular} & \begin{tabular}{|c|} 
CUSTO DE \\
ENERGIA / \\
seg ALÇA 02
\end{tabular} & $\begin{array}{c}\text { DESPESA } \\
\text { DE } \\
\text { ENTREGA }\end{array}$ & $\begin{array}{c}\text { RECEITA } \\
\text { UNITÁRIA }\end{array}$ & $\begin{array}{c}\text { COMISSÃO } \\
\text { SOBRE } \\
\text { VENDA }\end{array}$ & $\begin{array}{c}\text { GASTO } \\
\text { UNITÁRIO } \\
\text { TOTAL }\end{array}$ & MCU \\
\hline 1 & 0,64 & 1,62 & 33 & 0,001 & 0,00165097 & 0,057 & 2,464 & 8,0 & 0,00808 & 0,000082549 & 0,0649 & 3,90 & 0,0312 & 1,404682 & 2,49532 \\
\hline 2 & 0,638 & 1,62 & 44 & 0,001 & 0,00185735 & 0,057 & 2,464 & 8,0 & 0,00808 & 0,000082549 & 0,0649 & 4,00 & 0,04 & 1,449679 & 2,55032 \\
\hline 3 & 0,646 & 1,62 & 37 & 0,001 & 0,00175416 & 0,057 & 2,464 & 8,0 & 0,00808 & 0,000082549 & 0,0649 & 3,80 & 0,0228 & 1,421212 & 2,37879 \\
\hline 4 & 0,643 & 1,62 & 37 & 0,001 & 0,00175416 & 0,057 & 2,464 & 8,0 & 0,00808 & 0,000082549 & 0,0649 & 3,90 & 0,0312 & 1,424602 & 2,47540 \\
\hline 5 & 0,646 & 1,62 & 36 & 0,001 & 0,00165097 & 0,057 & 2,464 & 8,0 & 0,00808 & 0,000082549 & 0,0649 & 3,80 & 0,0228 & 1,414533 & 2,38547 \\
\hline 6 & 0,64 & 1,62 & 39 & 0,001 & 0,00175416 & 0,057 & 2,464 & 8,0 & 0,00808 & 0,000082549 & 0,0649 & 4,00 & 0,04 & 1,434091 & 2,56591 \\
\hline 7 & 0,641 & 1,62 & 35 & 0,001 & 0,00185735 & 0,057 & 2,464 & 8,0 & 0,00808 & 0,000082549 & 0,0649 & 3,80 & 0,0228 & 1,410885 & 2,38911 \\
\hline 8 & 0,634 & 1,62 & 31 & 0,001 & 0,00175416 & 0,057 & 2,464 & 8,0 & 0,00808 & 0,000082549 & 0,0649 & 3,90 & 0,0312 & 1,392473 & 2,50753 \\
\hline 9 & 0,645 & 1,62 & 41 & 0,001 & 0,00165097 & 0,057 & 2,464 & 8,0 & 0,00808 & 0,000082549 & 0,0649 & 4,00 & 0,04 & 1,443779 & 2,55622 \\
\hline 10 & 0,652 & 1,62 & 31 & 0,001 & 0,00185735 & 0,057 & 2,464 & 8,0 & 0,00808 & 0,000082549 & 0,0649 & 4,00 & 0,04 & 1,434632 & 2,56537 \\
\hline 11 & 0,639 & 1,62 & 34 & 0,001 & 0,00175416 & 0,057 & 2,464 & 8,0 & 0,00808 & 0,000082549 & 0,0649 & 3,80 & 0,0228 & 1,400972 & 2,39903 \\
\hline 12 & 0,653 & 1,62 & 38 & 0,001 & 0,00175416 & 0,057 & 2,464 & 8,0 & 0,00808 & 0,000082549 & 0,0649 & 3,70 & 0,0148 & 1,427752 & 2,27225 \\
\hline 13 & 0,634 & 1,62 & 27 & 0,001 & 0,00185735 & 0,057 & 2,464 & 8,0 & 0,00808 & 0,000082549 & 0,0649 & 3,90 & 0,0312 & 1,383946 & 2,51605 \\
\hline 14 & 0,65 & 1,62 & 42 & 0,001 & 0,00185735 & 0,057 & 2,464 & 8,0 & 0,00808 & 0,000082549 & 0,0649 & 3,90 & 0,0312 & 1,455008 & 2,44499 \\
\hline 15 & 0,643 & 1,62 & 30 & 0,001 & 0,00175416 & 0,057 & 2,464 & 8,0 & 0,00808 & 0,000082549 & 0,0649 & 3,90 & 0,0312 & 1,404654 & 2,49535 \\
\hline 16 & 0,639 & 1,62 & 33 & 0,001 & 0,00185735 & 0,057 & 2,464 & 8,0 & 0,00808 & 0,000082549 & 0,0649 & 3,90 & 0,0312 & 1,410033 & 2,48997 \\
\hline 17 & 0,642 & 1,62 & 29 & 0,001 & 0,00175416 & 0,057 & 2,464 & 8,0 & 0,00808 & 0,000082549 & 0,0649 & 3,90 & 0,0312 & 1,400134 & 2,49987 \\
\hline 18 & 0,643 & 1,62 & 41 & 0,001 & 0,00185735 & 0,057 & 2,464 & 8,0 & 0,00808 & 0,000082549 & 0,0649 & 4,00 & 0,04 & 1,449162 & 2,55084 \\
\hline 19 & 0,645 & 1,62 & 43 & 0,001 & 0,00175416 & 0,057 & 2,464 & 8,0 & 0,00808 & 0,000082549 & 0,0649 & 3,90 & 0,0312 & 1,44504 & 2,45496 \\
\hline 20 & 0,634 & 1,62 & 40 & 0,001 & 0,00185735 & 0,057 & 2,464 & 8,0 & 0,00808 & 0,000082549 & 0,0649 & 4,00 & 0,04 & 1,431175 & 2,56883 \\
\hline 21 & 0,639 & 1,62 & 36 & 0,001 & 0,00175416 & 0,057 & 2,464 & 8,0 & 0,00808 & 0,000082549 & 0,0649 & 3,70 & 0,0148 & 1,398672 & 2,30133 \\
\hline 22 & 0,639 & 1,62 & 36 & 0,001 & 0,00185735 & 0,057 & 2,464 & 8,0 & 0,00808 & 0,000082549 & 0,0649 & 3,90 & 0,0312 & 1,418901 & 2,48110 \\
\hline 23 & 0,639 & 1,62 & 25 & 0,001 & 0,00185735 & 0,057 & 2,464 & 8,0 & 0,00808 & 0,000082549 & 0,0649 & 4,00 & 0,04 & 1,395185 & 2,60482 \\
\hline 24 & 0,649 & 1,62 & 36 & 0,001 & 0,00175416 & 0,057 & 2,464 & 8,0 & 0,00808 & 0,000082549 & 0,0649 & 4,00 & 0,0400 & 1,440573 & 2,55943 \\
\hline 25 & 0,638 & 1,62 & 38 & 0,001 & 0,00175416 & 0,057 & 2,464 & 8,0 & 0,00808 & 0,000082549 & 0,0649 & 3,90 & 0,0312 & 1,419101 & 2,48090 \\
\hline 26 & 0,635 & 1,62 & 31 & 0,001 & 0,00165097 & 0,057 & 2,464 & 8,0 & 0,00808 & 0,000082549 & 0,0649 & 3,90 & 0,0312 & 1,390845 & 2,50915 \\
\hline 27 & 0,649 & 1,62 & 37 & 0,001 & 0,00175416 & 0,057 & 2,464 & 8,0 & 0,00808 & 0,000082549 & 0,0649 & 3,90 & 0,0312 & 1,434622 & 2,46538 \\
\hline 28 & 0,639 & 1,62 & 40 & 0,001 & 0,00175416 & 0,057 & 2,464 & 8,0 & 0,00808 & 0,000082549 & 0,0649 & 3,80 & 0,0228 & 1,41807 & 2,38193 \\
\hline 29 & 0,642 & 1,62 & 41 & 0,001 & 0,00185735 & 0,057 & 2,464 & 8,0 & 0,00808 & 0,000082549 & 0,0649 & 3,80 & 0,0228 & 1,430292 & 2,36971 \\
\hline 30 & 0,641 & 1,62 & 35 & 0,001 & 0,00175416 & 0,057 & 2,464 & 8,0 & 0,00808 & 0,000082549 & 0,0649 & 3,90 & 0,0312 & 1,415562 & 2,48444 \\
\hline
\end{tabular}

As MCU's geradas foram projetadas na forma de uma função densidade de probabilidade. A partir dessa função, determinou-se a Margem de Contribuição Unitária Esperada para o mês de outubro de cada tipo de produto. Para tal, foi aplicada estatística descritiva na forma de média através da utilização do software MINITAB ${ }^{\circledR}$ 15.0. A figura 3 mostra os valores da MCUE para outubro de 2007 de todos os produtos com destaque ao produto Balde para Construção (BCON): 


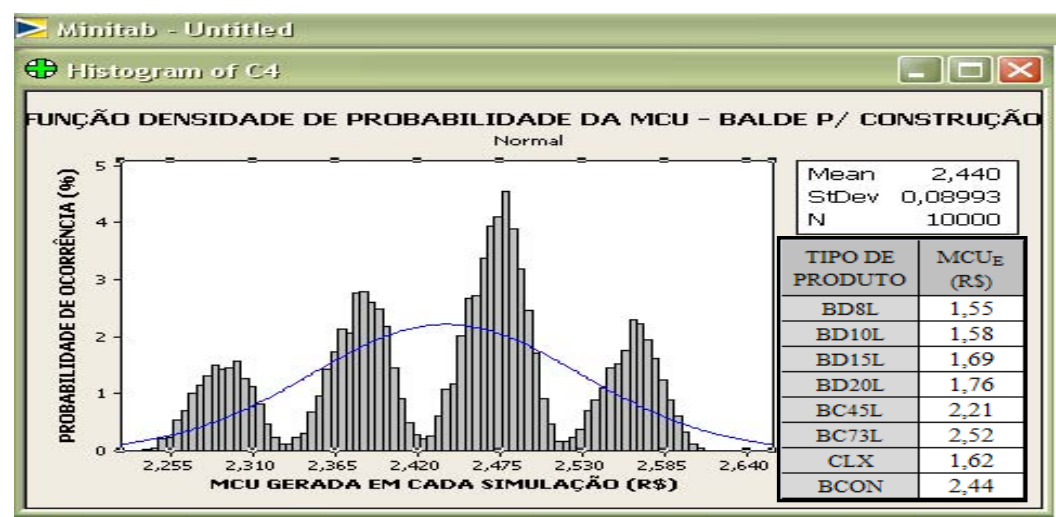

Figura 3 - Determinação da MCUE do produto BCON a partir do software MINITAB® 15.0

\subsubsection{Etapa 4 - analisar e projetar demanda e necessidade de produção}

Para a consecução dos valores obtidos nesta etapa, foi realizado um levantamento histórico da demanda pelos produtos da empresa. Em seguida, utilizou-se um método quantitativo de previsão de demanda, o da média móvel ponderada, e se projetou a demanda para o mês de outubro de 2007. Destaca-se que os valores obtidos representam os pedidos em carteira unidos à demanda aleatória pelos produtos. De posse desses valores, para a determinação da necessidade de produção de cada tipo de produto, fez-se o uso da expressão matemática 7 . Os valores obtidos encontram-se no quadro 12 :

\begin{tabular}{|c|c|c|c|c|c|c|c|c|c|c||c|}
\hline \multirow{2}{*}{$\begin{array}{c}\text { TIPO DE } \\
\text { PRODUTO }\end{array}$} & JAN & FEV & MAR & ABR & MAI & JUN & JUL & AGO & SET & $\begin{array}{c}\text { PREVISÃO DE } \\
\text { DEMANDA (OUT) }\end{array}$ & $\begin{array}{c}\text { NECESSIDADE DE } \\
\text { PRODUÇÃO (OUT) }\end{array}$ \\
\hline BD8L & 135.100 & 133.650 & 154.100 & 150.825 & 109.900 & 96.700 & 104.665 & 127.412 & 135.500 & 145.736 & 150.244 \\
\hline BD10L & 71.000 & 67.725 & 99.850 & 53.600 & 57.575 & 76.225 & 61.650 & 79.675 & 94.925 & 90.098 & 92.885 \\
\hline BD15L & 55.000 & 50.647 & 18.425 & 32.450 & 50.650 & 24.550 & 50.750 & 56.850 & 36.400 & 52.209 & 53.824 \\
\hline BD20L & 51.220 & 46.950 & 18.860 & 41.500 & 11.100 & 37.150 & 42.250 & 49.325 & 50.650 & 46.683 & 48.127 \\
\hline BC45L & 23.225 & 18.200 & 17.275 & 22.425 & 4.600 & 21.625 & 14.950 & 25.575 & 20.925 & 22.408 & 23.102 \\
\hline BC73L & 1.540 & 7.540 & 11.150 & 5.740 & 9.640 & 13.395 & 7.725 & 6.200 & 4.545 & 11.218 & 11.565 \\
\hline CLX & 5.550 & 4.820 & 24.080 & 9.680 & 29.466 & 15.660 & 6.860 & 8.320 & 28.433 & 24.147 & 24.894 \\
\hline BCON & 45.200 & 43.450 & 47.325 & 39.125 & 35.400 & 36.375 & 42.350 & 41.975 & 60.125 & 54.986 & 56.687 \\
\hline \hline TOTAL & 387.835 & 372.982 & 391.065 & 355.345 & 308.331 & 321.680 & 331.200 & 395.332 & 431.503 & 447.485 & $\mathbf{4 6 1 . 3 2 8}$ \\
\hline
\end{tabular}

Quadro 12 - Previsão de demanda e necessidade de produção para o mês de outubro de 2007

\subsubsection{Etapa 5 - verificar existência de recurso com restrição de capacidade e calcular a sua disponibilidade}

Partindo do pressuposto de que a empresa não estava sujeita a restrições relativas ao fornecimento de matéria-prima e de mão-de-obra para a fabricação dos produtos, verificou-se que a limitação do processo produtivo poderia corresponder à disponibilidade das máquinas para operação. Destaca-se que o valor encontrado foi expresso em segundos, unidade de tempo padrão do corrente estudo.

A partir de informações coletadas junto a técnicos do Setor de Planejamento e Controle da Produção, constatou-se que a empresa trabalhava em três turnos de oito horas de segunda a domingo. Assim, para o mês de outubro, foi previsto que empresa entraria em operação nos trinta e um dias disponíveis do período. De posse desses valores, determinou-se a capacidade nominal máxima de processamento. Em seguida, foi realizado um levantamento para determinação dos fatores que reduziriam a capacidade nominal máxima em cada tipo de máquina, a 
saber: tempo médio mensal designado para realização de manutenção (corretiva e preventiva), tempo médio de setup e o tempo despendido na fabricação de produtos não conformes. A partir desta análise, projetou-se que a capacidade real máxima de processamento (disponibilidade) das máquinas INJ AB, INJ MN e INJ XY seria de 11.449.440 segundos. Quando confrontando com a necessidade de produção projetada para o mês de outubro de 2007, o tempo disponível para fabricação verificou-se como uma restrição ao processo produtivo. Com isso, conseguiu-se estabelecer a métrica econômica que considera o consumo unitário de RRC para alicerçar a decisão do mix de produtos do período, conforme seção seguinte.

\subsubsection{Etapa 6 - determinar a $M C U_{E}$ sobre o consumo esperado de RRC para cada produto}

Os valores de consumo unitário de RRC, considerando que este se tratava do somatório das disponibilidades das máquinas injetoras, correspondiam ao tempo que cada produto levava para ser fabricado, ou seja, o Tempo de Ciclo. Com isso, similarmente ao procedimento adotado na determinação das MCU's esperadas, foram calculados os consumos unitários de RRC para cada tipo de produto esperados para o mês de outubro de 2007. Para tal, os TC's encontrados em cada simulação foram projetados na forma de função densidade de probabilidade. Em seguida, para cada tipo de produto, extraiu-se a média dos TC's através da utilização do software $\mathrm{MINITAB} \otimes$ 15.0. A figura 4 mostra a determinação do Consumo de RRCE dos produtos, destacando BCON:

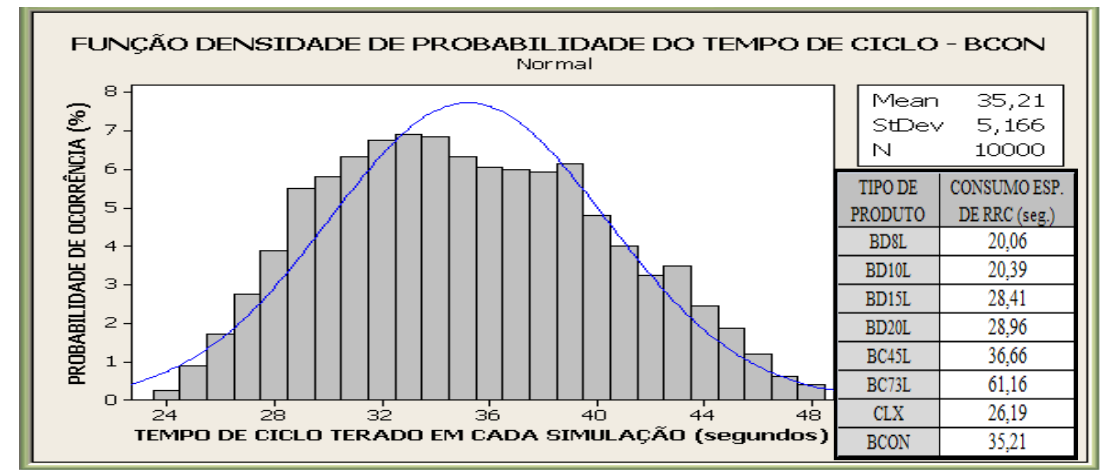

Figura 4 - Determinação do Consumo de RRC esperado do produto BCON a partir do software MINITAB ${ }^{\circledR} 15.0$

De posse das MCU's e dos consumos unitários de RRC esperados, definiuse, para cada tipo de produto, a métrica econômica para priorização da produção e venda dos produtos da empresa para o período em análise e planejamento. Para tal, fez-se o uso da expressão 8. Os valores encontrados e a priorização estabelecida são apresentados no quadro 13. Vale destacar que a ordem de prioridade é diferente quando comparado com o simples uso da MCUE como critério. 


\begin{tabular}{|c|c|c|c|c|c|}
\hline $\begin{array}{c}\text { TIPO DE } \\
\text { PRODUTO }\end{array}$ & $\begin{array}{c}\text { MCUE } \\
(\mathrm{R} \$)\end{array}$ & $\begin{array}{c}\text { CONSUMO ESPERADO DE } \\
\text { UNIDADES DE RRC (TEMPO DE } \\
\text { MÁQUINA EM SEGUNDOS) }\end{array}$ & $\begin{array}{c}\text { MCUE / CONSUMO DE RRCE } \\
\text { (R\$ / TEMPO DE MÁQUINA) }\end{array}$ & $\begin{array}{c}\text { PRIORIDADE DE } \\
\text { PRODUÇÃO E VENDA } \\
\text { (PARÂMETRO: MCUE) }\end{array}$ & $\begin{array}{c}\text { PRIORIDADE DE PRODUÇÃO E } \\
\text { VENDA (PARÂMETRO: MCUE / } \\
\text { CONSUMO DE RRCE) }\end{array}$ \\
\hline BD8L & 1,55 & 20,06 & 0,0771 & $8^{\circ}$ & $2^{\circ}$ \\
\hline BD10L & 1,58 & 20,39 & 0,0773 & $7^{\circ}$ & $1^{\circ}$ \\
\hline BD15L & 1,69 & 28,41 & 0,0597 & $4^{\circ}$ & $7^{\circ}$ \\
\hline BD20L & 1,76 & 28,96 & 0,0608 & $3^{\circ}$ & $5^{\circ}$ \\
\hline BC45L & 2,21 & 36,66 & 0,0602 & $1^{\circ}$ & $6^{\circ}$ \\
\hline BC73L & 2,52 & 61,16 & 0,0412 & $6^{\circ}$ & $4^{\circ}$ \\
\hline CLX & 1,62 & 26,19 & 0,0618 & $2^{\circ}$ & \\
\hline BCON & 2,44 & 35,21 & 0,0693 & $3^{\circ}$ \\
\hline
\end{tabular}

Quadro 13 - Priorização da produção e venda dos produtos para o mês de outubro de 2007 com base no consumo unitário de RRC

A partir da priorização estabelecida com base no consumo unitário de RRC, definiu-se o mix de produção e venda dos produtos, como mostra a seção seguinte.

\subsubsection{Etapa 7 - determinar mix de produtos com base na $\mathrm{MCU}_{\mathrm{E}}$ sobre $\mathrm{o}$ consumo de RRC $\mathrm{E}_{\mathrm{E}}$}

De posse das MCUE e dos consumos esperados de RRC de cada produto, aliado ao valor correspondente à capacidade real máxima da fábrica, ou seja, a disponibilidade total das máquinas, estabeleceu-se o mix de produção e venda dos produtos de forma a maximizar a MCTE da empresa. O resultado gerado é apresentado no quadro 14:

\begin{tabular}{|c|c|c|c|c|c|c|c|c|c|c|}
\hline $\begin{array}{c}\text { TIPO DE } \\
\text { PRODUTO }\end{array}$ & $\begin{array}{c}\text { DEMANDA } \\
\text { PREVISTA } \\
\text { (OUT/2007) }\end{array}$ & $\begin{array}{c}\mathrm{MCU}_{\mathrm{E}} \\
(\mathrm{RS})\end{array}$ & $\begin{array}{l}\text { NECESSIDADE DE } \\
\text { PRODUÇÃ̃O } \\
(1,03 \times \text { DEMANDA })\end{array}$ & $\begin{array}{c}\text { PRIORIDADE DE } \\
\text { PRODUÇÃO E VENDA } \\
\text { (PARÂMETRO: } \text { MCU }_{\text {E }} / \\
\text { CONSUMO DE RRCE) }\end{array}$ & $\begin{array}{c}\text { MIX DE } \\
\text { PRODUÇÃ̃O }\end{array}$ & $\begin{array}{c}\text { CONSUMO ESPERADO } \\
\text { DE UNIDADES DE RRC } \\
\text { (TEMPO DE MÁQUINA } \\
\text { EM SEGUNDOS) }\end{array}$ & $\begin{array}{c}\text { CAPACIDADE } \\
\text { CONSUMIDA } \\
\text { (RRC) (\%) }\end{array}$ & $\begin{array}{c}\text { CAPACIDADE } \\
\text { RESTANTE (\%) }\end{array}$ & $\left|\begin{array}{c}\text { MIX DE VENDAS } \\
\text { (PRODUÇÃ̃O x 0,97) }\end{array}\right|$ & $\begin{array}{c}\text { MARGEM DE } \\
\text { CONTRIBUIÇÃO } \\
\text { TOTAL } \\
\text { ESPERADA (R\$) }\end{array}$ \\
\hline BD10L & 90.098 & 1,58 & 92.885 & $1^{\circ}$ & 92.885 & 20,39 & $16,55 \%$ & $83,45 \%$ & 90.098 & $142.035,60$ \\
\hline BD8L & 145.736 & \begin{tabular}{|l|}
1,55 \\
\end{tabular} & 150.244 & $2^{\circ}$ & 150.244 & 20,06 & $26,33 \%$ & $57,13 \%$ & 145.736 & 225.398,18 \\
\hline BCON & 54.986 & \begin{tabular}{|l|}
2,44 \\
\end{tabular} & 56.687 & $3^{\circ}$ & 56.687 & 35,21 & $17,43 \%$ & $39,69 \%$ & 54.986 & $134.239,18$ \\
\hline CLX & 24.147 & \begin{tabular}{|l|}
1,62 \\
\end{tabular} & 24.894 & $4^{\circ}$ & 24.894 & 26,19 & $5,69 \%$ & $34,00 \%$ & 24.147 & $39.061,27$ \\
\hline BD20L & 46.683 & \begin{tabular}{|l|}
1,76 \\
\end{tabular} & 48.127 & $5^{\circ}$ & 48.127 & 28,96 & $12,17 \%$ & $21,83 \%$ & 46.683 & $82.180,27$ \\
\hline BC45L & 22.408 & \begin{tabular}{|l|}
2,21 \\
\end{tabular} & 23.102 & $6^{\circ}$ & 23.102 & 36,66 & $7,40 \%$ & $14,43 \%$ & 22.408 & $49.465,90$ \\
\hline BD15L & 52.209 & \begin{tabular}{|l|}
1,69 \\
\end{tabular} & 53.824 & $7^{\circ}$ & 53.824 & 28,41 & $13,35 \%$ & $1,08 \%$ & 52.209 & $88.488,35$ \\
\hline BC73L & 11.218 & \begin{tabular}{|l|}
2,52 \\
\end{tabular} & 11.565 & $8^{\circ}$ & 2.014 & 61,16 & $1,08 \%$ & $0,00 \%$ & 1.954 & $4.923,96$ \\
\hline TOTAL & 447.485 & - & 461.328 & - & 451.777 & - & $100,00 \%$ & - & 438.221 & $765.792,71$ \\
\hline
\end{tabular}

Quadro 14 - MCT esperada para o mês de outubro de 2007, obtida a partir da métrica econômica de priorização da produção e venda que considera o consumo unitário de RRC

Destaca-se que, ao se determinar o mix somente utilizando a MCUE como critério, obteve-se uma MCTE de $\mathrm{R} \$ 745.462,42$ e uma demanda atendida de 419.246 produtos, ou seja, $2,73 \%$ e $4,53 \%$ menores que os resultados, respectivamente, gerados pelo método para decisão de mix de produtos proposto (MCT de R\$765.792,71 e 438.221 unidades vendidas). Tanto pela ótica da quantidade de pedidos atendida, quanto pela da MCTE gerada, definiu-se, devido à existência de restrição de capacidade, o mix de produtos com base na métrica econômica proposta em detrimento da baseada exclusivamente MCUE provinda da Contabilidade Gerencial tradicional. Desta forma, a empresa condicionou-se a obter um maior resultado econômico e a conseguir atender um maior número de solicitações, gerando uma menor quantidade de back orders.

Vale ressaltar que os resultados obtidos com a aplicação da métrica econômica para alicerçar a decisão de mix de produtos poderiam ser ainda melhores caso a empresa conseguisse ampliar a sua capacidade produtiva. Para tal, poder- 
se-ia tentar reduzir o tempo de setup das máquinas, diminuir o tempo despendido na fabricação de produtos defeituosos a partir da adoção de ferramentas da qualidade, dentre outras ações. Além disso, os gestores da empresa poderiam empreender ações, junto aos fornecedores de matéria-prima, para a consecução de plástico reciclado de melhor qualidade, o que acarretaria em uma redução da variabilidade do processo produtivo tanto em termos de consumo de material, como também de tempo de fabricação de cada produto.

\section{CONSIDERAÇÕES FINAIS}

Este estudo apresentou um método de caráter quantitativo e econômico para auxiliar a tomada de decisão de mix de produtos a partir da união de conceitos provindos da Contabilidade Gerencial e da Pesquisa Operacional. Especificamente para o caso em que uma empresa manufatureira operava com uma acentuada variabilidade de custos unitários, realizou-se a aplicação da simulação de Monte Carlo de forma conjunta à Margem de Contribuição e ao conceito de consumo unitário de RRC na definição de uma métrica econômica para alicerçar a priorização de produção e venda dos produtos, ou seja, a decisão de mix de produtos da empresa. Assim, conseguiu-se responder à pergunta de pesquisa para a qual o estudo foi direcionado.

No exemplo didático utilizado para ilustrar a aplicação do método proposto, pôde-se observar que o conhecimento detalhado da estrutura dos custos e despesas, dos preços de venda e do processo produtivo da empresa verificou-se imprescindível para a determinação dos produtos que mais contribuíam para a maximização do resultado econômico da empresa, além de servir como uma base confiável para a tomada de decisão gerencial. Destaca-se que um acompanhamento contínuo dos custos e despesas deve ser realizado pelos gestores para que ações corretivas imediatas possam ser tomadas no momento em que ocorrerem variações acentuadas. Fazer essa análise desses custos e despesas requer disciplina e determinação, além de demandar amplo esforço, porém, proporciona resultados imediatos podem ajudar a empresa a tomar decisões de mix de produtos mais precisas.

Como ponto forte deste estudo, pode-se destacar a simplicidade da aplicação da Margem de Contribuição aliada ao conceito de consumo unitário de RRC e à simulação de Monte Carlo. Além disso, a projeção de cenários proporcionou uma visão econômica solidificada para a empresa tomar a decisão de produção e venda de produtos. Outro ponto a destacar relaciona-se com o fato de o estudo ter feito o uso de variados conceitos e ferramentas computacionais que podem ser aproveitados em outras situações. Ressalta-se, ainda, que a integração de procedimentos de simulação com a análise gerencial de custos, despesas, preços de vendas e processo produtivo constituiu-se como um diferencial positivo deste trabalho. Finalmente, pode ser destacada a transcorrência deste estudo em vários aspectos relacionados ao processo industrial, importante ambiente de atuação profissional do Engenheiro de Produção.

Dentre as limitações do trabalho, destaca-se a pouca análise realizada em relação aos fatores não estritamente econômicos que podem influenciar a decisão de mix de produtos, como a possibilidade de fidelização de clientes. Outro ponto 
passível de maior análise diz respeito à qualidade dos produtos fabricados pela empresa, qualidade esta que pode fazer o preço cobrado tornar-se maior e o gap entre a demanda e a necessidade de produção ser diminuído. Portanto, o método proposto não deve ser utilizado sozinho, mas em conjunto com outras ferramentas e informações, tendo em vista o pleno conhecimento das condições dos clientes e concorrentes da empresa. Convém observar que, apesar de tratar um caso em que os custos utilizados no cálculo da MCU são considerados como variáveis e diretos, reconhece-se que a classificação de custos não é um processo simples quando se leva em consideração um horizonte de curto prazo, o que pode limitar a aplicação do método proposto em outros contextos empresariais. Como limitação final, destacase a consideração de apenas uma restrição no processo produtivo analisado (no caso, a capacidade das máquinas de injeção). Essa consideração nem sempre é verdadeira, já que ambientes de manufatura podem apresentar múltiplas restrições devido a limitações de capacidade em termos de mão-de-obra, de matéria-prima e de outras atividades produtivas (para mais detalhes sobre decisão de mix de produtos em ambientes com múltiplas restrições, consultar Fredendall e Lea (1997)).

Por fim, idealiza-se que este trabalho contribua como um referencial teórico para outros estudos que envolvam a decisão de mix de produtos dentro do campo de conhecimento da gestão econômica de organizações.

\begin{abstract}
This paper aims to present the use of the Monte Carlo simulation to define metrics to support product-mix decision in a company in which products have great variability in costs per unit. To attain this purpose, a seven-step model built from the integration of Monte Carlo simulation with Contribution Margin concept, coming from Managerial Accounting, is proposed. The method is applied from a didactic example which uses real data achieved through a field research carried out in a Brazilian plastic products factory that employ recycled material. Finally, it is concluded that the Monte Carlo simulation is effective for treating costs per unit variability and that the proposed method is useful to support decision-making related to product-mix.
\end{abstract}

Keywords: product-mix decision, Monte Carlo simulation, costs per unit variability

\title{
REFERÊNCIAS
}

ABIPLAST. Perfil da indústria brasileira de transformação de material plástico, 2008. Disponível em: <http://www.abiplast.org.br/upload/File/Perfil2008/PERFIL_2008.zip>. Acesso em: 01/10/2010.

ASSEF, R. Gerência de Preços como Ferramenta de Marketing. Rio de Janeiro: Campus, 2005. 
BANKS, J.; CARSON, J.; NELSON, B. Discrete-event system simulation. New Jersey: Prentice Hall, 1996.

BRUNI, A. L. Administração de custos, preços e lucros. São Paulo: Atlas, 2006. BUFFA, E. S. Modern Production Management. 4th ed. New York: John Willey \& Sons, 1973.

CEMPRE. Negócios e Oportunidades. CEMPRE informa, nº 66, 2002. Disponível em: <Http://cempre.tecnologia.ws/cempre_informa.php?lnk=ci_2002-

1112_inter.php>, acesso em 06/04/09.

COGAN, S. Contabilidade Gerencial: uma abordagem da teoria das restrições. São Paulo: Saraiva, 2007.

CORBETT NETO, T. Contabilidade de Ganhos: a nova contabilidade gerencial de acordo com a teoria das restrições. São Paulo: Nobel, 1997.

COX, J.; SPENCER, M. S. The Constraints Management Handbook. New York: St. Lucie Press, 1998.

DAVIS, M. M.; AQUILANO, N. J.; CHASE, R. B. Fundamentals of Operations Management. Boston: Irwin McGraw Hill, 1999.

DEMMY, S.; TALBOTT, J. Improve internal reporting with ABC and TOC. Management Accounting, v. 80, n. 5, p. 18-24, 1998.

ESCUDERO, L. F. La simulación en la empresa. Bilbao: Ediciones Deusto, 1973.

FOSTER, B. P.; S. J. BAXENDALE. The absorption vs. direct costing debate. Cost Management, v. 22, n. 4, p. 40-48, 2008.

FREDENDALL, L. D.; LEA, B. R. Improving the product mix heuristic in the theory of constraints. International Journal of Production Research, v. 35, n. 6, p. 1535-1544, 1997

GARRISON, R. H.; NOREEN, E. W.; BREWER, P. C. Managerial Accounting. 11th ed. New York: McGraw Hill, 2006.

GENTLE, J. E. Random Number Generation and Monte Carlo Methods. New York: Springer, 2003.

GIL, A. C. Como elaborar projetos de pesquisa. 4ª ed. São Paulo: Atlas, 2002.

HILLIER, F. S.; LIEBERMAN, G. J. Introduction to Operations Research. 6th ed. New York: McGraw Hill, 1995.

LEONE, G. G. Custos: um enfoque administrativo. 13a ed. Rio de Janeiro: Fundação Getúlio Vargas, 2000. 
LINHARES, A. Theory of constraints and the combinatorial complexity of the product mix decision. International Journal of Production Economics, v. 121, n. 1, p. 121-129, 2009

LUSTOSA, P. R. B.; PONTE, V. M. R.; DOMINAS, W. R. Simulação. In: CORRAR, L. J.; THEÒPHILO, C. R. (Org.). Pesquisa Operacional para decisão em contabilidade e administração. São Paulo: Atlas, 2004.

MARCONI, M. A.; LAKATOS, E. M. Fundamentos de Metodologia Científica. $6^{\mathrm{a}}$ ed. São Paulo: Atlas, 2008.

MARTINS, E. Contabilidade de Custos. 9a ed. São Paulo: Atlas, 2006.

METROPOLIS, N. The beginning of the Monte Carlo method. Los Alamos Science, 1987, p. 125-130. Disponível em: <http://library.lanl.gov/la-pubs/00326866.pdf>. Acesso em: 01/01/2010.

METROPOLIS, N.; ULAM, S. The Monte Carlo method. Journal of the American Statistical Association, v. 44, n. 247, p. 335-341. 1949.

MOORE, J. H., WEATHERFORD, L. R. Decision modeling with Microsoft Excel. 6th ed. New Jersey: Prentice Hall, 2001.

PADOVEZE, C. L. Curso Básico Gerencial de Custos. $2^{\mathrm{a}}$ ed. São Paulo: Pioneira Thomson Learning, 2006.

PIDD, M. Modelagem empresarial: ferramentas para tomada de decisão. Porto Alegre: Artes Médicas Sul, 1996.

PRADO, D. Teoria das Filas e da Simulação, 2a ed. Nova Lima: INDG, 2004.

SHAMBLIN, J. E.; STEVENS, G. T. Operations research: a fundamental approach. New York: McGraw-Hill, 1974.

SINGH, R. K.; PRAKASH, K. S.; TIWARI, M. K. Psycho-clonal based approach to solve a TOC product mix decision problem. International Journal of Advanced Manufacturing Technology, v. 29, n. 11-12, p. 1194-1202, 2006

WINSTON, W. L. Operations research: applications and algorithms. 3rd ed. Belmont: Duxbury Press, 1994.

YIN, R. K. Estudo de Caso: planejamento e método. $3^{a}$ ed. Porto Alegre: Bookman, 2005. 